\title{
The efficacy of biodegradable mesh as a fixation device for support of autogenous onlay bone grafts: $A$ radiographic and histomorphometric analysis.
}

A thesis submitted to McGill University in partial fulfillment of the requirements of the degree of Master's of Science

Badr Al-Jandan, B.D.S.

Supervisor:

Dr. Timothy Head

Graduate and Postdoctoral Studies

Faculty of Dentistry

McGill University

Montreal, (Quebec), Canada December 2007

Copyright $(2007$ Badr Al-Jandan 


$\begin{array}{ll}\begin{array}{l}\text { Library and } \\ \text { Archives Canada }\end{array} & \begin{array}{l}\text { Bibliothèque et } \\ \text { Archives Canada }\end{array} \\ \begin{array}{l}\text { Published Heritage } \\ \text { Branch }\end{array} & \begin{array}{l}\text { Direction du } \\ \text { Patrimoine de l'édition }\end{array} \\ \begin{array}{l}\text { 395 Wellington Street } \\ \text { Ottawa ON K1A 0N4 } \\ \text { Canada }\end{array} & \begin{array}{l}\text { 395, rue Wellington } \\ \text { Ottawa ON K1A 0N4 } \\ \text { Canada }\end{array}\end{array}$

Your file Votre référence ISBN: 978-0-494-51062-9

Our file Notre référence

ISBN: 978-0-494-51062-9

NOTICE:

The author has granted a nonexclusive license allowing Library and Archives Canada to reproduce, publish, archive, preserve, conserve, communicate to the public by telecommunication or on the Internet, loan, distribute and sell theses worldwide, for commercial or noncommercial purposes, in microform, paper, electronic and/or any other formats.

The author retains copyright ownership and moral rights in this thesis. Neither the thesis nor substantial extracts from it may be printed or otherwise reproduced without the author's permission.
AVIS:

L'auteur a accordé une licence non exclusive permettant à la Bibliothèque et Archives Canada de reproduire, publier, archiver, sauvegarder, conserver, transmettre au public par télécommunication ou par l'Internet, prêter, distribuer et vendre des thèses partout dans le monde, à des fins commerciales ou autres, sur support microforme, papier, électronique et/ou autres formats.

L'auteur conserve la propriété du droit d'auteur et des droits moraux qui protège cette thèse. $\mathrm{Ni}$ la thèse ni des extraits substantiels de celle-ci ne doivent être imprimés ou autrement reproduits sans son autorisation.
In compliance with the Canadian Privacy Act some supporting forms may have been removed from this thesis.

While these forms may be included in the document page count, their removal does not represent any loss of content from the thesis.
Conformément à la loi canadienne sur la protection de la vie privée, quelques formulaires secondaires ont été enlevés de cette thèse.

Bien que ces formulaires aient inclus dans la pagination, il n'y aura aucun contenu manquant.

\section{Canada}




\section{TABLE OF CONTENT}

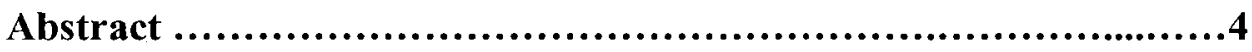

Acknowledgements................................................6

\section{CHAPTER ONE (INTRODUCTION AND BACK GROUND)}

General Introduction.................................................

Non-vascularized autogenic bone grafts ...........................8

General principles

Types of bone grafts

Physiology of Autogenic bone graft healing

Inlay versus onlay bone graft

Cancellous versus cortical bone graft:

Guided Bone Regeneration (GBR).

General principles

Types of GBR materials

Titanium mesh

Biodegradable mesh

Synopsis

\section{CHAPTER TWO (MATERIALS AND METHODS)}

Experimental Model ................................................23

Treatment Groups...................................................23

Experiment Device..................................................24

Preparation and Anesthetic Technique..............................25

Operative Procedure.................................................25

Post Operative Care.................................................28

Post-Mortem Assessment and Preparation...........................29

Micro-CT analysis

Histologic preparation and assessment 
CHAPTER THREE (RESULTS)

Clinical Course......................................................33

Titanium group (Control) ........................................33

Gross description:

Micro-CT analysis

Histologic Description

Histomorphometric Analysis

Biodegradable group (Test)..............................................38

Gross description:

Micro-CT analysis

Histologic Description

Histomorphometric Analysis

Comparing Titanium and biodegradable groups ......................43

\section{CHAPTER FOUR (DISCUSSION AND CONCLUSION)}

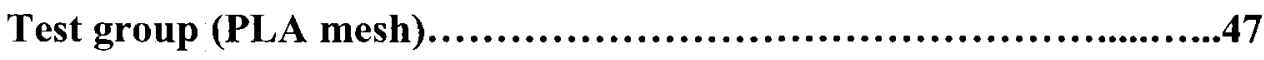

Control group (Ti mesh)...........................................49

Conclusion and recommendations....................................51

\section{OTHERS:}

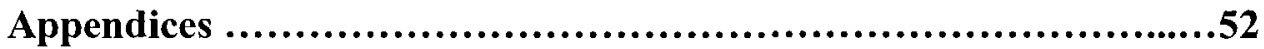

References........................................................63 


\begin{abstract}
Objective: The objective of this study is to test the efficacy of the biodegradable mesh as an alternative fixation device to the titanium mesh for support of onlay particulate, bone and cancellous, marrow (PBCM) grafts. Two parameters were evaluated: 1) Bone graft volume maintenance and 2) Calcified tissue surface area and distribution. Methods: 12 New Zealand white rabbits were used and divided equally into two groups. In both groups, endochondral, cancellous bone graft was harvested from the anterior ilium. The bone graft was then compressed and placed as an onlay onto the lateral aspect of the mandible using two chambers for each animal. In the control group, the chambers were made of titanium, however in the test group the chambers were made of poly L-lactide, polyglycolide and trimethylene carbonate mesh (Inion GTR $^{\mathrm{TM}}$, Finland), and thereafter the chambers were fixed to the mandible. The animals were then sacrificed after eight weeks postoperatively, and then MicroCT imaging was performed for the entire sample in order to determine the total volume of calcified tissue present under each chamber. In addition, Histologic sections were obtained from each chamber, and thereafter stained using Toluidine

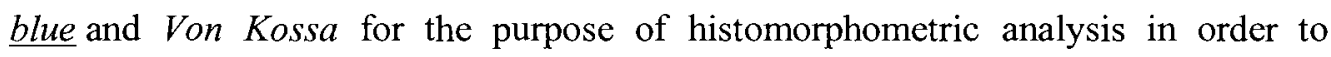
determine the calcified tissue surface area. Results: When comparing the data from both the titanium (Ti) and the biodegradable mesh (PLA) groups, Micro CT analysis showed no significant statistical difference $(P$ - value $=0.546)$ with regard to the percentage of bone found under the chambers (Ti $15.0 \%$ and PLA 13.83\%).Interestingly, neither did the histomorphometric analysis show any significant statistical deference $(P$-value $=0.8272)$ with regard to the percentage of calcified tissue surface area (Ti 16.86\% and PLA 16.17\%). Moreover, this calcified tissue was also found to be evenly distributed in both groups. Conclusion: Biodegradable mesh made of poly L-lactic and polyglycolic acid copolymers appears to be an appropriate alternative to the Ti mesh for support of PBCM bone grafts. However, further clinical trails should be conducted to confirm these findings.
\end{abstract}


Objective: L'objective de cet étude est de tester l'efficacité de la membrane biodégradable, comme une alternative pour fixation de la greffe osseuse poreux et moelleux. Deux paramètres sont évaluées : 1) le volume de greffe maintenu, et 2 ) superficie et distribution de tissue calcifiée. Méthodes : douze lapins blancs de la Nouvelle Zélande sont utilisés. Les sujets sont divisés en deux groups. Dans chaque group, greffes endochondrales sont collectées de l'ilium antérieur. La greffe est comprimée et placée en surface, de la surface latérale de la mandibule en deux chambres séparées pour chaque animal. Pour le group de control, les chambres sont faites en titane; et pour le group testé, les chambres sont faites en acide poly-lactique, de polyglycolide et carbonate de trimethylene (Inion GTRTM, Finlande). Les animaux sont sacrifiés après huit semaines après les opérations, et l'imagerie CT est utilisée pour l'ensemble du spécimen, enfin de déterminer le volume total de tissue calcifié sous chaque chambre. En plus, les sections histologiques sont obtenues de chaque chambre et colorés avec les méthodes de bleu de Toluidine et de Von Kossa, enfin de déterminer la superficie de la tissue calcifiée. Résultats : Quand les donnés des deux groups, le group de titane (Ti) et le group des matériels biodégradable (PLA), sont comparés, les analyses de CT démontre aucune différence significative (valeur $\mathrm{P}=0.546$ ) en terme du pourcentage de volume d'os trouvé dans les chambres $(\mathrm{Ti}=15.0 \%, \mathrm{PLA}=13.83 \%)$. Il faut aussi noter que les analyses histomorphométriques ont aussi obtenue de résultats similaires $(\mathrm{P}=0.8272)$, en termes de superficie du tissue calcifiée $(\mathrm{Ti}=16.86 \%, \mathrm{PLA}=16.17 \%)$. En plus, la distribution de tissue calcifié est uniforme dans deux groups. Conclusion : Les membranes biodégradable, fabriquées des copolymères d'acides poly-L-lactiques et poly-glycolique sont apparemment des alternatives appropriées des membranes en titane pour le support des greffes PBCM. Cependant, des études cliniques plus approfondies sont nécessaire pour confirmer ces résultats. 


\section{ACKNOWLEDGEMENTS}

I am deeply indebted to Dr. T.W. Head, my supervisor, who was very helpful in guiding me in my work.

I would also like to thank the F.O.R.C.E Alumni Foundation for funding this research project \& Stryker Canada for providing the titanium screws that were used in the experiment.

I would like to thank Dr. Abdullah Al-Harkan, my friend and colleague, who kindly provided general assistance, encouragement and great ideas throughout all phases of this experimental study.

I am also thankful to Dr. Janet Henderson and Dr. Adam Hacking, who helped design and manufacture the titanium mesh and who also made their bone laboratory available to us. They were kindly available for help and guidance throughout the entire experiment. Moreover, I am grateful to Dr. Letitia Lim, for her great effort in performing the Micro-CT analysis \& preparing the histology slides.

And finally, I am also grateful to my wife, Ghalia for all her great support and patience. 


\section{CHAPTER ONE INTRODUCTION AND BACKGROUND}

\subsubsection{GENERAL INTRODUCTION}

Dental implants have become one of the most predictable modalities for treatment of patients who are completely or partially edentulous. The physiological healing of dental implants depends on the principle of osseointegration; which is defined as "a process whereby clinically asymptomatic, rigid fixation of alloplastic materials is achieved, and maintained in bone during functional loading "(Brånemark et al. 1969). In order to successfully achieve this principle, fulfillment of the following two criteria are required: 1)minimal hard tissue injury during implant site preparation to maximize the availability and survival of osteoprogenitor cells, and 2) primary stability of the dental implant which is directly dependent on the quality and availability of sufficient bone volume ( including both height and width). Among others, these former criteria are critical factors in determining the long-term success of dental implants (Brånemark et. al. 1999 ; Albrektsson et. al. 2001).

Frequently, dental implant placement is complicated by the absence of sufficient alveolar bone volume. In order to overcome this problem, bone grafting procedures have been developed to reconstruct various types of bone defects. Several types of graft materials have been used including autogenous, allogenic, xenogenic, and alloplastic. The literature confirms that, autogenous bone grafts are the gold standard for the reconstruction of alveolar and basal jaw bone deformities (Marx et. al. 1993, 2002). In contrast to other grafting materials they provide superior results, especially with regards to primary osteogenesis, osteoinduction, and resorption with bone remodeling. Autogenous bone grafts have been used in different forms, including corticocancellous blocks, cortical chips, particulate bone and cancellous 
marrow grafts (PBCM), and in corticocancellous chips. Bone grafting procedures have been improved with the development of the principle of "Guided Bone Regeneration" (GBR). This concept uses an occlusive barrier in order to provide graft stability and prevent the invasion of competing, nonosteogenic cells derived from the surrounding soft tissue (Kostopoulos et al. 1994, Karring et. al.1995).Different types of barriers have been described in the literature, including membranes and meshes (both resorbable and nonresorbable).Each of these systems carries its stated advantages and disadvantages, these barriers will be discussed in detail in the following sections.

\subsubsection{NON-VASCULARIZED AUTOGENIC BONE GRAFTS}

\subsubsection{General principles;}

The concept of "Bone Graft Incorporation" is defined as; fusion of the bone graft to the recipient site, which is followed by bone remodeling and eventually leading to the formation of a more mature bone, thus enabling the bone graft to withstand continuous functional loading (El-Hakim, 2006). Bone graft revascularization is considered the initial step of bone graft incorporation (Burchardt et. al. 1983). Thereafter, it depends on a combination of the following three mechanisms: osteogenesis, osteoinduction and osteoconduction (El-Hakim, 2006).

Osteogenesis is defined as the formation of new bone from osteoprogenitor cells. The osteoprogenitor cells either arise from the recipient site or are transplanted into the wound by the graft material. Osteoinduction refers to the ability of the graft to stimulate mesenchymal stem cells and osteoblasts at the recipient site, in order to form new bone. These cells are triggered by other osteoprogenitor cells and / or the production of growth factors ( BMP's, TGF-B, etc.). Osteoconduction is the process by which a bone graft material provides a scaffold to guide the new bone formation, and thereafter resorb and be replaced by new bone. 


\subsubsection{Types of bone grafts}

Numerous bone graft materials are available for clinical use including; autogenic, allogenic, alloplastic, and xenogenic bone graft materials .To a varying degree, all autogenic bone grafts are capable of producing the three mechanisms that are essential for bone graft incorporation (osteogenesis, osteoinduction and osteoconduction). Among all available types of bone augmentation materials they are still considered the most ideal (Marx et al 1993,2002). Multiple donor sites are available for harvesting autogenous bone grafts including intraoral sites (symphsis, external oblique ridge, and maxillary tuburosity etc.) or extraoral donor sites (anterior and posterior iliac crest, tibia, calvarium etc.).Appropriate donor site selection depends on several factors such as the quantity and quality of bone required for the reconstruction, and patient preference.

Unlike autogenous bone grafts, allogenic bone grafts provide only osteoconductive and osteoinductive properties, due to the fact that There are no viable cells available to induce osteogenesis (Moghadam et al. 2004). This type of bone graft material however carries the risk of infectious disease transmission and/ or allergic reaction. (Yildirim et al. 2000)

The alloplastic bone graft materials have only osteoconductive properties. Jensen and coworkers (1998) have reported favorable clinical outcome when using alloplastic bone graft materials, although these materials require prolonged bone healing periods when compared to autogenous bone grafts (Jensen et. al. 1998). These materials however have the advantage of being available in unlimited supplies. On the other hand, some alloplastic bone materials have been found to cause bone growth inhibition (Moghadam et al. 2004; Stavropoulos et al. 2003).

In contrast to autogenic bone grafts, xenogenic bone graft materials are only osteoconductive. Their bone generation potential is considered to be 
inferior when compared to autografts (Tuominen et al. 2001). In an in-vivo experiment, Schmid \& coworkers, showed that bovine bone substitute (Bio$O s S^{\circledR}$ ) is only osteoconductive in the initial stages of bone healing (Schmid et al. 1997). Moreover, In another experimental study, Slotte \& Lundgren (1999), evaluated the potential of bone generation using bovine bone substitutes( Bio-Oss $\left.{ }^{\circledR}\right)$.This study demonstrated that Bio-Oss ${ }^{\circledR}$ arrested bone formation when compared to the controlled group(empty chambers). Moreover, other experimental studies have also shown that bovine bone substitutes (Bio-Oss ${ }^{\circledR}$ ) inhibited bone formation (Stavropoulos et al. 2001,2003 ). In addition, xenografts do however have the same advantage as alloplastic bone grafts, being available in an unlimited supply.

In summary, among all types of bone graft materials that are available, autogenic bone grafts provide the capability of producing the three mechanisms that are essential for bone graft incorporation; osteogenesis, osteoinduction and osteoconduction. Various bone graft materials (i.e. allogenic, alloplastic, and xenogenic) are now being used in clinical practice. It has not been concluded however that these materials are equivalent to autogenic bone grafts. Thus among all these types of bone substitutes, autogenic bone grafts are still considered the gold standard.

\subsubsection{Physiology of autogenic bone graft healing (The two phase theory)}

In 1956 the "two phase theory of osteogenesis" was introduced. (Axhausen et al. 1956). This theory states that, when bone is transplanted from one area to another within the same individual, the healing of this bone graft will occur in two phases. Phase I (The cellular phase), starts immediately since viable cells survive transplantation via plasmatic diffusion of oxygen and nutrients. Under these circumstances the cells that are likely to survive these events are osteoblasts. Unlike osteoblasts, osteocytes survive only if they are located at a distance less than $0.3 \mathrm{~mm}$ from the mineralized tissue surface. The cells that have survived the transplantation will proliferate and 
deposit osteoid. The end result of this phase is the formation of an unorganized and immature bone. The PBCM will then complete the revascularization over a two week period (Albrektsson et al. 1980 ;Burchardt et al. 1983). Phase two (maturation and remodeling phase) begins in the second week after bone transplantation and it becomes critical 4-5 weeks following bone transplantation. This stage involves osteogenesis which is derived from the host recipient site. Growth factors that are (BMP's, etc) released from the bone graft also contribute to the osteoinduction of the recipient bed. The bone remodeling will convert the immature bone that was formed in phase (I) to a more organized lamellar bone. The clinical implication of phase (II) is to determine the quality of the generated bone, and to facilitate the bone graft incorporation potential. However, the quantity of the generated bone is determined by phase (I).

In order to achieve the maximum graft quantity, phase (I) of the bone graft healing process should be optimized. Marx et al. (1993) have made the following suggestion for further optimizing phase (I) bone graft healing. First, harvest of cellular bone and condense this graft material to enhance the cellular density of the transplanted cells. Second, the transplanted cells must be kept viable during the harvest and storage period. It has been shown (Marx et al, 1993) that $95 \%$ of the bone graft will remain viable for up to four hours at room temperatures, when preserved in normal saline. Third, the recipient tissue bed must have sufficient vasculature to support nutritional diffusion and development of capillary ingrowth. Finally, the graft must be immobilized to insure good revascularization.

\subsubsection{Inlay versus onlay bone graft}

Rosenthal and Buchman (2003) demonstrated that inlay bone grafts exhibit increased volumes with time, in contrast to onlay bone grafts which resorb with time .In addition these authors ( Rosenthal \& Buchman ,2003) have also shown that when the bone grafts are placed as an inlay, there is no 
significant advantage of cortical bone grafts over PBCM grafts with regard to bone graft volume maintenance. However, when bone grafts are placed as an onlay, the cortical bone graft maintained a higher bone volume (Ozaki and Buchman, 1998).It is also clear in the literature (animal studies and clinical trials) that inlay bone grafts maintain greater bone volume when compared to onlay grafts (Ozaki and Buchman, 1998).

The concept of the "biological boundaries" is defined as; predetermined genetically derived body boundaries that remain constant. Therefore, when bone grafts are placed in a location in which bone is normally present (inlay) they are shielded from the soft tissue envelope recoil forces, and thus are subjected to identical physical forces to those received by the surrounding bone. These conditions improving the bone graft incorporation and healing potential. In addition there is an increased bone surface contact area between the bone graft and the native bone. This feature improves the bone graft incorporation potential (El-Hakim, 2006). In contrast, onlay bone grafts will not benefit from these previously stated advantages that are related to inlay bone grafting; due to the fact that the bone grafts are placed beyond the biological boundaries. In reference to these preceding studies (Rosenthal \& Buchman, 2003; Ozaki \& Buchman, 1998) it appears that onlay bone grafting procedures are more challenging when compared to inlay bone grafting procedures.

\subsubsection{Cancellous versus cortical bone graft:}

Cancellous bone graft has the advantage of early revascularization that starts at two days after bone graft transplantation and is usually completed by two weeks (Albrektsson et. al. 1980 ; Burchardt et. al. 1983). In contrast, cortical bone grafts have been found to be more resistant to revascularization. The revascularization of cortical bone graft usually starts after one week post implantation and is completed by 4-6 weeks (Gray et. al. 1979). Furthermore, cancellous bone grafts posses a two times faster osteogenesis potential 
compared to cortical bone grafts (Gray et. al. 1972). The majority of the osteogenic potential comes from stem cell precursors that are derived from the endosteum and marrow lining. Autogenous, particulate , bone and cancellous ,marrow grafts (PBCM) have been shown to be an excellent bone graft material for the reconstruction of many alveolar and basal bone defects in the jaws (Marx et. al. 1993, 2002). This is due to its high osteogenic potential (Gray et. al. 1972) and faster revascularization (Gray et. al. 1979) compared to that of cortical bone grafts .However, the major disadvantage of cancellous bone grafts when used as an onlay, is that it requires a fixation device (mesh, membrane, etc) in order to maintain the graft position and form during the bone healing process.

In summary, PBCM bone grafts are capable of producing the three mechanisms that are essential for bone graft incorporation (osteogenesis, osteoinduction and osteoconduction). Therefore, among all these types of bone augmentation materials that are available for clinical use, they are still considered the most ideal (Marx et al 1993, 2002). In addition, this bone graft material has the advantage of early revascularization, thus further improving the bone graft incorporation potential and making it more resistant to infection. All these previously stated advantages make PBCM grafts an excellent augmentation material for the reconstruction of many bone defects. However, this bone graft material (i.e. PBCM) does require a fixation device in order to maintain the graft position and form during the bone healing process (Marx et al. 1993, 2002)

\subsubsection{GUIDED BONE REGENERATION}

\subsubsection{General principles}

The concept of "guided bone regeneration" (GBR) consists of the creation of a space under occlusive barriers. This will allow only osteoprogenitor cells to migrate into the created space and thus prevent cells derived from soft tissues from invading the created space. Osteoprogenitor 
cells therefore benefit from lack of competition in forming tissue under the created space. This concept has been used successfully to generate bone in different patterns of alveolar bone defects (Kostopoulos et al. 1994 and Karring et al. 1995).

As discussed previously, onlay bone grafts present a great challenge with regards to growing and maintaining of bone volume. This is particularly true with PBCM onlay grafts .Multiple techniques and materials have been described to facilitate bone grafting outside the biological boundaries. These materials will be discussed in detail in the following sections.

\subsubsection{Types of GBR materials}

Various types of non-resorbable and bioabsorbable barriers have been used as GBR devices. For these devices to attain the concept of GBR, they should posses the following characteristics; biocompatibility, stability throughout the critical phases of bone graft healing, space maintenance, exclusion of undesired non-osteoprogenitor cells, and being easy to use (McAllister et al. 2007).

There are numerous non- resorbable barriers that are now available for clinical use such as; expanded polytetrafluoroethylene (ePTFE), titanium reinforced $e P T F E$, high-density $P T F E$, or titanium mesh. These ePTFE barriers have been studied extensively in both animal experiments and human trails (Buser et. al. 1993, 1995), thus confirming that the ePTFE barriers are an excellent GBR device (Buser et. al. 1993, 1995; Bartee 1995). The use of titanium mesh as a barrier maximizes graft containment and avoids problems related to barrier collapse (McAllister et al 2007). Multiple experimental and clinical studies have been preformed in order to verify the effectiveness of the titanium meshes as a GBR device. These studies have shown reduced bone graft resorption when titanium mesh was used in alveolar bone reconstruction (Von Arx et al. 1996, 1998). Titanium meshes are used in clinical practice due 
to the following advantages: excellent stability and tissue compatibility, reduced inflammatory response, and osteocoductivity (Von Arx et. al. 1996, 1998).

To overcome some of the limitations of non-resorbable barriers, such as the need for a second surgical procedure for their removal, they have been largely replaced with biodegradable barriers (McAllister et al 2007). Biodegradable barriers currently in clinical use fall into two broad categories: natural or synthetic. Natural products are made of various types of collagen that are derived from animal origins. Synthetic products are made of poly alpha-hydroxy acid polymers, primarily polylactic and polyglycolic acid copolymers. The two types of resorbable barriers differ in their modes of resorption; with collagen products undergoing enzymatic degradation while synthetic barriers are degraded by hydrolysis (McAllister et al. 2007). Although collagen barriers offer improved soft tissue response, they lacked the ability to maintain adequate defect space to facilitate bone generation(McAllister et al. 2007). Meshes composed of co-polymers such as polylactic acid (PLA) and polyglycolic acid (PGA) have been shown to provide adequate graft stability throughout the critical stages of bone healing, with no evidence of inflammation (Kinoshita $Y$ et al. 1997). From these examples of resorbable and non-resorbable membranes and meshes, titanium and PLA/PLG meshes will be discussed in detail.

\subsubsection{Titanium mesh}

Multiple types of titanium meshes with varying thickness are available (perforated or solid, micro/macro-porous) each of which has its own advantages and disadvantage. Yamada et al. (2003), evaluated bone regeneration in occlusive titanium caps with and without perforations in a rabbit model. The author reported substantial fibrous connective tissue ingrowths in the perforated caps group, this tissue ingrowth resulted in prevention of new bone formation under the perforated caps. A consensus is 
not however available with regard to the best mesh to be used in order to facilitate the bone regeneration process.

Von Arx et. al. (1996), published a case report in which they described a new technique for guided bone regeneration, using a microporous titanium mesh to stabilize autogenous bone grafts that were harvested from the mandible (chin or retromolar area), where the basic role of the mesh was graft stabilization. Excellent graft results were obtained due to; excellent tissue compatibility, minimal clinical and histological inflammation when mesh was exposed, and geometric stability. However, the disadvantage of using the titanium mesh is that it requires a second surgical intervention for its removal.

In a clinical trial, Von Arx et. al (1998), evaluated the clinical and radiographic healing of dental implants placed in alveolar ridges that had insufficient bone volume and that had been previously augmented using the same titanium mesh technique mentioned above. The cohort of patients was followed for one to three years after implant loading. Interestingly, the authors found that loaded dental implants which had been inserted into an augmented alveolar ridge demonstrate clinical and radiographic findings similar to those of implants placed into a pristine ridge.

In a prospective clinical study, Von Arx et al. (1999), evaluated bone regeneration around dental implants and peri-implant bone defects, which had been augmented as previously mentioned. After a six month post-operative period, the titanium mesh and micro-screws were removed and bone regeneration was assessed. The mean bone fill was $93 \%$ of the bony defects and the overall healing course was excellent. Thus, this study concluded that a micro titanium mesh in combination with autogenous bone grafts is effective for the treatment of peri-implant bone defects. 
In summary, the titanium mesh maximizes graft containment and prevents the collapse of the created space, thus allowing bone formation (McAllister et al 2007). In addition, animal experiments and clinical trails confirm the effectiveness of the titanium meshes in the GBR procedures. Interestingly, these studies have shown reduced bone grafts resorption when covered with a titanium mesh in alveolar bone reconstruction (Von Arx et. al. 1996, 1998).Furthermore, titanium meshes are used in clinical practice due to the following advantages; excellent stability and tissue compatibility, reduced inflammatory response, and osteocoductivuty (Von Arx et. al. 1996, 1998). Given the positive outcomes reported, the use of microporous titanium mesh is an adequate means of stabilizing autogenous PBCM grafts. However, in order to overcome the need for mesh removal, researchers began to work on developing resorbable materials having the same desirable physical properties as the titanium mesh.

\subsubsection{Biodegradable mesh}

Research into resorbable meshes has focused primarily on two synthetic poly alpha-hydroxy acid polymers ;polylactic and polyglycolic acid. These biodegradable materials have undergone extensive investigations in vitro as well as in several animal models and clinical trials (Eppley et. al. 1996, 1997; Ferretti et. al. 2002; Edwards et. al. 2001; Cox et. al. 2003; Landes 2003).

Initial results following clinical applications using polylactic and polyglycolic acid fixation devices for the treatment of facial fractures, and maxillary and mandibular osteotomies has been promising (Eppley et. al. 1996, 1997; Ferretti et. al. 2002; Edwards et. al. 2001; Cox et. al. 2003; Landes 2003). Interestingly, these clinical trials seemed to demonstrate that biodegradable plates are biocompatible, structurally adequate to provide uncomplicated bone healing and completely biodegradable after varying lengths of time. However, some potential postoperative problems of poly-L- 
lactic acid have also been reported. These complications include foreign body reactions and fluctuant swelling at the implantation site (Bergsma et. al. 1993). The foreign body reaction is most likely caused by the high degradation rate resulting in a large amounts of residual metabolic byproducts .Polymer combinations have been developed in an attempt to overcome these major disadvantages of the available degradable devices and also to improve their physical characteristics.

Eppley et al. (1997) evaluated the healing of a calvarial, inlay corticocancellous blocks using a rabbit model. A $5 \times 10 \mathrm{~mm}$ block was harvested from the parietal bone. The bone graft block was then rotated 180 degree to its original orientation and was stabilized with either a titanium mesh or a biodegradable mesh (PLA/PLG). Both groups showed complete healing with no evidence of inflammation. With regard to the degradation of the biodegradable mesh, after two postoperative months there was no change in the physical shape of the biodegradable mesh (i.e. appeared identical to when it was originally placed). Significant physical changes to the mesh outline occurred after 6 months, and there was complete degradation of the mesh after 9 months.

Meinig et al. (1997) found that a resorbable poly (L-lactide) membrane facilitated osseous regeneration across a diaphyseal defect, without any evidence of local inflammation. Interestingly, in the control group (not covered with a membrane) the defects were found to be filled with muscle and soft tissue. In the study group however the membrane appeared to function as an excellent GBR device; excluding soft tissues invasion, thus allowing direct bone formation in the created defects.

Kinoshita $Y$ et al. (1997) reported the results of a study in a canine model which evaluated the reconstruction of continuity defects in the mandible using a poly L-lactic acid (PLLA) mesh tray and particulate 
cancellous bone and marrow (PCBM). Eight adult dogs were divided into two groups of four dogs each. In group A, each dog had a tray fixed with stainless steel wires on each side of the mandibular stumps, with the tray's concave surface attached to the inferior border of the mandible (U-fixation). In group $B$, the concave surface was attached to the superior border (inverted Ufixation). Each tray was filled with PCBM from the iliac crest and the animals were then scarified at 3,6, and 12 months respectively. All animals underwent radiographic and histological evaluation. In group A (U-fixation), complete healing of the continuity mandibular bone defects occurred after 3 months, yet fibrous tissue had invaded through the area above the tray, resulting in a poorly shaped alveolar ridge. Interestingly, in group B (inverted U-fixation); there was complete healing of the bony defect with well-shaped alveolar ridges. This confirms the efficacy of PLLA meshes as a GBR device, where a more favorable alveolar ridge form being observed in the group that was covered with a PLLA sheet (i.e. inverted U-fixation group).

Kinoshita $Y$ et al. (1993) evaluated the following; 1) inflammatory response related to the degradation of Poly L-lactide acid (PLLA) meshes, 2) the rate of bone formation within the cylinder and 3)the material mechanical strength. The PLLA meshes were formed into a cylinder and filled with PCBM bone graft. The PLLA meshes were then implanted subcutaneously into the back of 22 adult dogs, for a one- year period. Polypropylene (PP) mesh was used as a control. The results showed no inflammatory infiltration around PLLA meshes. The bone formation reached its peak one month after implantation and was mostly observed along the inner wall of the cylinder, while the PLLA meshes retained $80 \%$ of their initial strength for the first three months. The author concluded that PCBM graft supported by PLLA mesh would be very effective in the reconstruction of bone defects.

Sireno et al. (2003) did a clinical study to evaluate the biodegradable sponge made of polylactide-polyglycolide acid (Fisiografts Ghimas, Bologna, 
Italy) as a filler material for the preservation of the alveolar ridge following dental extractions. There were two groups. In the first (test) group the extraction socket, was filled with PLA/PGA sponge and in the second (control) group the extraction socket, was left to be filled with blood clot. After 6 months, a $6 \times 3 \mathrm{~mm}$ core sample was harvested from the center of the socket using a trephine. Two parameters were evaluated; the alveolar bone width and the percentage of mineralized tissue. The results of this study indicate that there was $0.2 \mathrm{~mm}$ bone loss of alveolar width in the control group; in contrast there was $0.7 \mathrm{~mm}$ bone gain in the test group. With regard to the histomorphometric analysis of the percentage of mineralized tissue; in the test group there was $67 \%$ in contrast to the control group which showed $56 \%$ of bone. The author concluded that alveolar bone resorption following dental extraction may be prevented or reduced by the use of this material.

Nieminen et al (2006), preformed an experiment using the sheep model .The aim of this study was to assess the degradation of poly L-lactide, polyglycolide and trimethylene carbonate mesh (Inion GTR, Finland) dipped into an N-methyl-2-pyrroline (NMP) solution and fixed onto the lateral aspect of the mandible. The animals were sacrificed at 6, 12, 26, 52 and 104 weeks postoperatively. At 6-26 weeks, the mesh was present and surrounded by a fibrous connective tissue. At 52- 104 weeks, the mesh and fibrous networks were non-detectable. Foreign body reaction was not observed. Complete degradation of the membrane was observed after 12 months.

Rimondini et al. (2005) performed an in vivo experimental study using a rabbit femoral condyle model to evaluate bone regeneration in critical bone defects using injectable bioabsorbable PLA / PGA dispersed in a hydrosoluble matrix. The authors concluded that the experimental material is able to enhance bone healing in critical bone defects. Histomorphometric data demonstrated bone maturation improved from 30 to 90 days with the concomitant degradation of the material. Complete healing of the defect was 
observed at 3 months. This observation demonstrates this material's osteoconductive properties.

Imbronito et al. (2005) evaluated, in a rabbit tibia model, the ultrastructural healing pattern of bone defects filled with a copolymer of polylactic/polyglycolic acid, at a time point at which it was expected to be only partially degraded. In areas where the degrading copolymer was present in small amounts, newly formed bone matrix was detected. Bone formation took place concomitant with the degradation of PLA /PGA, thus confirming an osteoconductive nature of this material.

Guillermo et al. (2004) using a rabbit model, evaluated the efficiency of different fixation screws for support of onlay, autogenous, cortical bone graft blocks onto the mandible. The graft was harvested from the medial tibia, and the cortical block was then secured to the lateral aspect of the mandible by using either titanium, or a biodegradable screw (PLLA/PGA) or no fixation (control group). In both experimental groups, there was no evidence of graft mobility, there was obvious graft consolidation without any signs of foreign body reaction or inflammation. Interestingly, the control group (no fixation) showed no evidence of graft consolidation. This study shows that the biodegradable (PLLA/PGA) screws provide excellent initial graft stability, which in turn facilitated bone graft healing without evidence of inflammatory reaction.

In summary, biodegradable polyalpha-hydroxy acid polymers have under gone extensive research. The use of resorbable membranes made of combined polymers (co-polymers) has made it possible to overcome most of the historical disadvantages associated with the use of single polymers (homopolymers). Barriers composed of co-polymers have been found to be excellent osteoconductive devices (Imbronito et al. 2005; Rimondini et al. 2005). They have been shown to provide adequate graft stability throughout the critical 
stages of bone healing, for inlay grafts and with no evidence of inflammation (Eppley et al. 1997; Kinoshita et al. 1993, 1997; Nieminen et al 2006). However, studies testing the effectiveness of these barriers for support of PBCM as onlay bone grafts are still lacking .Given all these findings, mesh composed of copolymers would appear to be an appropriate substitute for conventional titanium meshes to support PBCM bone grafts.

\subsubsection{SYNOPSIS:}

PBCM bone grafts have been shown to be an excellent bone graft material for the reconstruction of many bone defects. However, this bone graft material requires a fixation device in order to maintain the graft position and form during healing (Marx et al. 1993, 2002).

The literature advocates the use of a titanium mesh fixation device for PBCM bone graft support (Von Arx et. al. 1996, 1998, 1999). The major disadvantage is that the mesh needs to be removed prior to or at the time of dental implant placement. This lengthens the surgical procedure and exposes the patient to a more extensive surgery.

The biodegradable mesh composed of co-polymers is known to be an excellent osteoconductive device, providing adequate support for inlay bone grafts with no evidence of inflammation (Eppley et al. 1997; Kinoshita et al. 1993, 1997; Nieminen et al 2006).Biodegradable mesh would Therefore appear to be an ideal substitute for titanium meshes for the support of PBCM as an onlay bone graft. 


\section{CHAPTER TWO \\ MATERIALS AND METHODS}

\subsubsection{EXPERIMENTAL MODEL:}

Adult New Zealand White (NZW) rabbits were used as the experimental animals. The NZW rabbit has been used extensively as a model for bone graft experiments in the maxillofacial skeleton. The rabbits' bone remodeling cycle is short ( $\operatorname{sigma}=6$ weeks) while for humans the sigma value is 17 weeks. Using the sigma ratio between human and rabbit, conclusions can be extrapolated from the rabbit model to human equivalents (Roberts $\&$ Garetto, 1999).

Adult female NZW rabbits, weighing 3.0 to $4.0 \mathrm{~kg}$ were obtained from the Charles River breeding facility. At least two weeks were allowed to quarantine the animals (between the purchase date and the experiment date). The animals were kept in individual cages at the Montreal General Hospital (MGH) Research Facility.

\subsubsection{TREATMENT GROUPS}

Twelve $(\mathrm{N}=12)$ New Zealand white rabbits were used and divided equally into two groups. In both groups, endochondral, PBCM bone graft was harvested from the anterior ilium of the animal (Figure 1). The bone graft was placed as an onlay on the lateral aspect of the mandible using two chambers (Figure 4). One chamber was on the ramus of the mandible and the other chamber was on the body. In one group, the chambers were made of titanium(Figure 4a), and in the other group, the chambers were made of biodegradable material; poly L-lactide, polyglycolide and trimethylene carbonate (Inion $G T R^{\mathrm{TM}}$, Finland) (Figure 4a) .The sample size for this experiment was calculated by Dr. Joseph Lawrence, using the "simple sample size calculator" software. Based on data derived from a previous experiment 
(El-Hakim, 2006), we chose a 95\% confidence level, a standard deviation of 1.5 and a total confidence width of 2.5 . The required sample size was found to be 12 rabbits $(\mathrm{N}=12)$

Based on random assignment, each animal received a single mesh (titanium or biodegradable) with two chambers. Both chambers were filled with autogenous, endochondral PBCM graft harvested from the anterior ilium. The mesh along with the PBCM grafts was stabilized and fixed on the right lateral aspect of the mandible, using retention screws for the titanium mesh and retention tacks for the biodegradable mesh group. The animals in each group were numbered subsequently from 1 to 6 .

\subsubsection{EXPERIMENT DEVICE}

\section{Group l: Biodegradable mesh (test group)}

A $0.2 \mathrm{~mm}$ dense porous poly L-lactide, polyglycolide and trimethylene carbonate mesh (Inion $G T R^{\mathrm{TM}}$, Finland) was softened and then molded to the desired shape by press forming the material over a plastic template. This template is a replica of the internal volume of the titanium mesh. Each mesh contained two equal chambers, each having a total volume of $50.9 \mathrm{~mm} 3$ (Figure 2 b).

\section{Group 2: Titanium mesh (control group)}

The titanium alloy mesh contained two prefabricated chambers and was identical in volume to those in the biodegradable mesh group (Figure 2 a).

\subsubsection{OPERATIVE TECHNIQUE}

To reduce variability, one surgeon performed all operative techniques. All animal handling such as injections and anesthesia was performed by MGH animal health technicians. All the manipulations and procedures performed on the rabbits were approved by the university veterinarian and the McGill University animal ethics committee (see Appendices II). 


\subsubsection{PREPARATION AND ANESTHETIC TECHNIQUE}

To acclimatize the animals, a period of at least two weeks was allowed between the purchase time and the surgery date. The animals were housed in individual cages and were given water and food. The animals were kept in a designated room at the MGH research institute. No animals developed signs of illness or loss of appetite; therefore no animals were excluded from the study.

Water and food was withheld from the animal 12 hours prior to the surgery. At one hour pre-operatively, the animals were sedated by injecting Butorphanol $0.3 \mathrm{mg} / \mathrm{kg}$ intra-muscular. Thereafter, the animal was brought to the operating room. Intravenous access was established by inserting a 22 gage catheter into the auricular vein. Next, general anesthesia was induced using a combination of drugs: Thiopental $(25 \mathrm{mg} / \mathrm{kg})$, Acepromazine $(0.75 \mathrm{mg} / \mathrm{kg})$ and Glycopyrolate $(0.01 \mathrm{mg} / \mathrm{kg})$. These drugs were injected intravenously and thereafter, the rabbit was intubated using a pediatric, uncuffed, endotracheal tube. General anesthesia was then maintained using $2-4 \%$ of Isoflurane inhalation agent. Afterward, the animals were connected to a mechanical ventilator (using an assisted ventilation mode) for the entire duration of the surgery. Later, all monitoring devices were applied. These monitors consisted of a pulse oximeter and a thermometer.

\subsubsection{OPERATIVE PROCEDURE}

The skin over the right submandibular (recipient site) and left anterior iliac crest (donor site) was shaved and prepped using a povidine solution. Next, Cefazolin (Novopharm Ltd., Toronto, Canada) $12.5 \mathrm{mg} / \mathrm{Kg}$ was administered intravenously, just prior to the surgery.

The animals were then placed on the right decubitus position and both surgical sites were draped. The donor site was approached first. A $2 \mathrm{~cm}$ skin incision was made from the anterior superior iliac spine extending posteriorly 
along the crest of the anterior ilium. The incision was extended through the skin, muscle and periosteum. This was followed by a subperiosteal dissection along the lateral aspect of the anterior ilium. A $1.5 \times 0.5 \mathrm{~cm}$ cortical bony window was removed in order to gain access to the cancellous bone(Figurel). Using bone curettes a total of $0.10 \mathrm{cc}$ of cancellous bone was harvested and then compressed in a tuberculin syringe. The bone was compressed into both chambers (identical for both titanium and biodegradable group) (Figure 2). The incisions were closed in two layers; 3.0 vicryl was used to close the muscle in a continuous fashion closure, followed by a 3.0 plain gut in a simple interrupted fashion for skin closure.

The animals were then turned and placed in the left decubitus position. $3 \mathrm{~cm}$ submandibular skin incision was made along the inferior border of the mandible, carried through skin, muscle and periosteum, to expose the inferior border of the mandible. This was followed by a subperiosteal dissection along the lateral aspect of the mandible (Figure $3 a$ ). Using a template; holes were drilled under the containers to expose the graft to the marrow space (Figure 3 b). Each animal received a single mesh (titanium or biodegradable) that contains two chambers . Next the mesh was adapted onto the right lateral border of the mandible. The titanium mesh was fixed using five screws (Figure 4a). Alternatively, five biodegradable tacks were used to fix the biodegradable mesh in place (Figure $4 b$ ). The incisions were closed in two layers; 3.0 vicryl was used to close the muscle in a continuous fashion closure, followed by a 3.0 plain gut in a simple interrupted fashion for skin closure. 

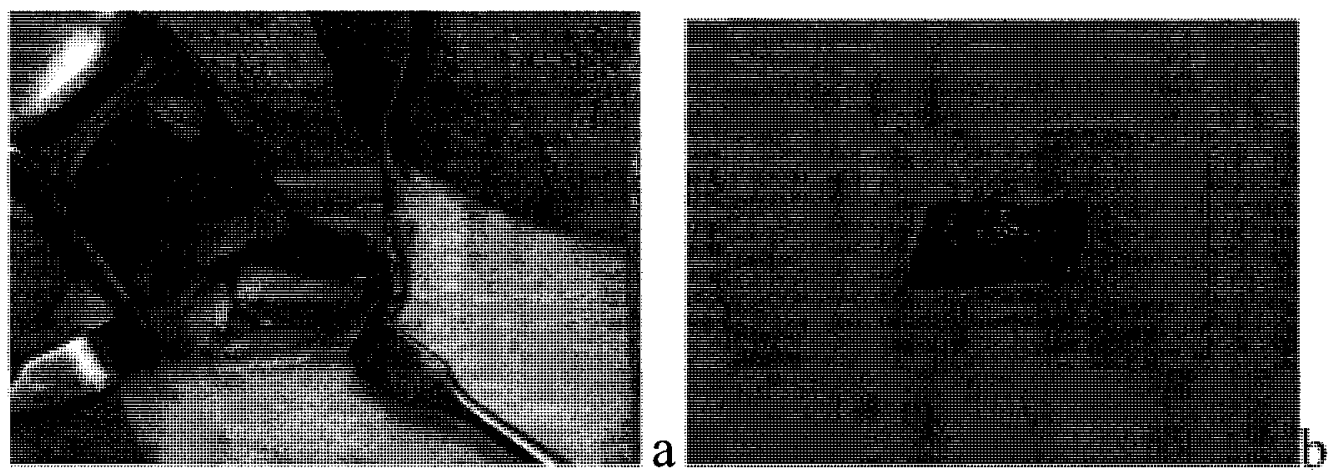

Figure 1. Donor site bone harvesting (anterior iliac crest) (a) and corticocancellous bone block (b)
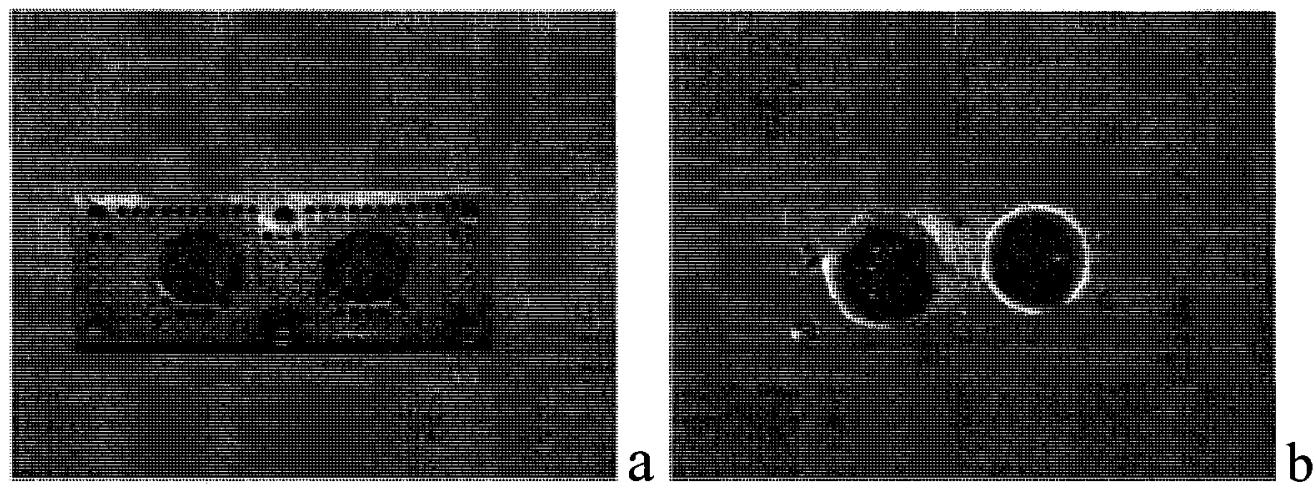

Figure 2. Compressed PBCM placed into the Ti (a) and PLA (b) meshes.
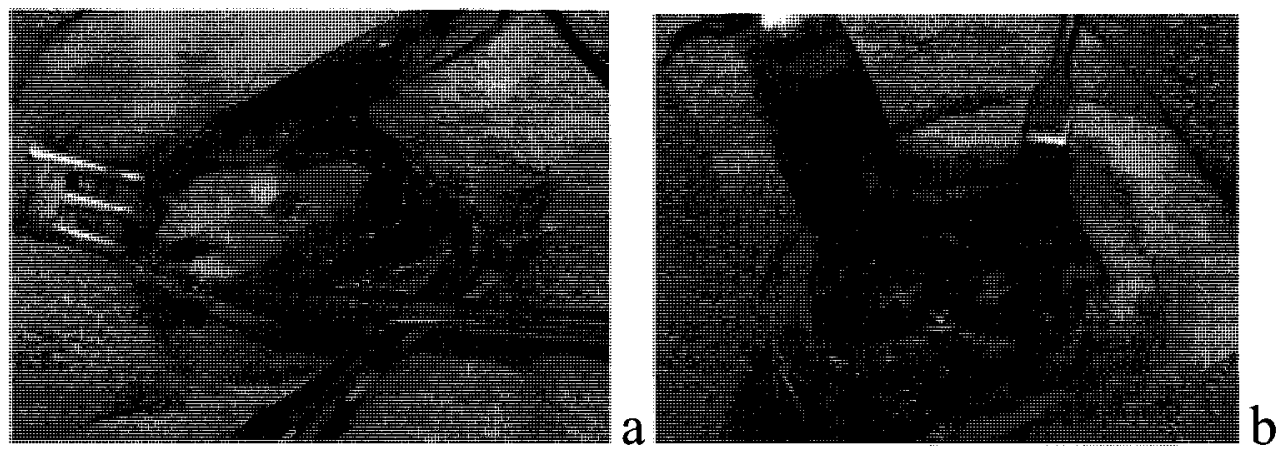

Figure 3. Exposure of the mandible (a) \& establishing bleeding points using a template (b) 

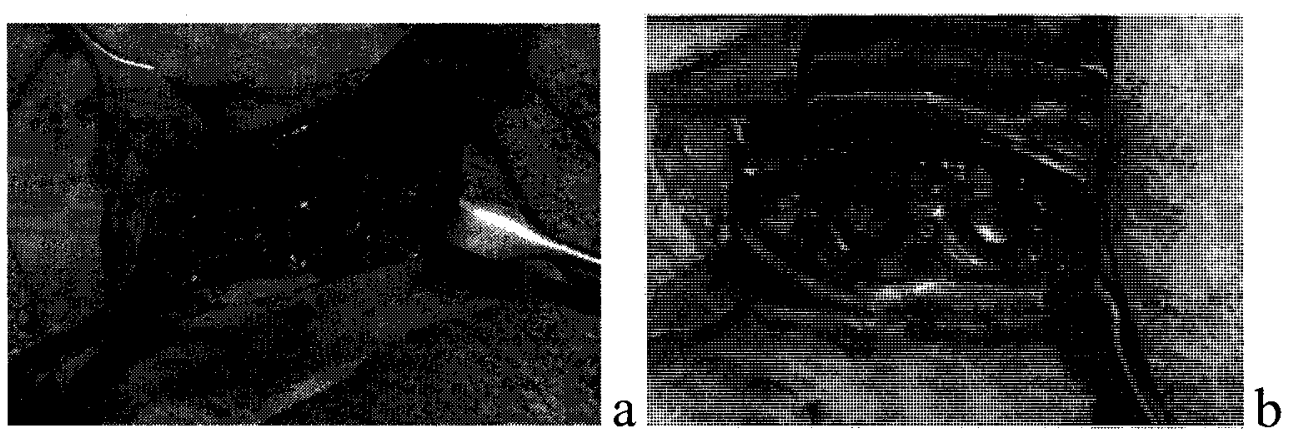

Figure 4. Ti (a) \& PLA (b) mesh, stabilized on the lateral aspect of the mandibule

\subsubsection{POST OPERATIVE CARE}

After the surgery was terminated the isoflurane was stopped and the animals were observed for spontaneous breathing. The animals were extubated after two minutes of regular spontaneous breathing and were kept under close monitoring for 30 minutes before they were sent to their cages. Chloromycetin succinate (Pfizer Canada Inc., Kirkland,QC, Canada) 25 $\mathrm{mg} / \mathrm{Kg}$ Q8h was given to all rabbits for 5 days through the intravenous route.

Buprenorphine (Reckitt Benckiser plc, Slough, UK) $0.04 \mathrm{mg} / \mathrm{Kg}$ IM was used every 12 hours to achieve analgesia. This was done regularly for 48 hours and then on an as-needed basis, according to a periodic evaluation of the animals by the technicians. All animals were given a liquid diet for 1 to 2 days post operatively and then fed with regular food as tolerated. All animals were examined and weighed twice a week by the animal health technicians. None of the animals showed any signs of infection or loss of more than $15 \%$ of their pre-operative weight. 


\subsubsection{POST-MORTEM ASSESSMENT AND PREPARATION}

\subsubsection{Animal Sacrifice}

All animals were sacrificed eight weeks following surgery. Butorphanol (Apothecon B.V., The Netherlands) $0.3 \mathrm{mg} / \mathrm{Kg}$ was given for sedation prior to sacrifice. Pentobarbital (J.M. Loveridge p.l.c., Southamton, $U K) 150 \mathrm{mg} / \mathrm{Kg}$ was then infused through an intraauricular intravenous cannula. After cessation of cardiac pulsation was confirmed by the animal health technician, the animals were transferred to the operating room. The right sides of the mandible were sharply dissected. An en bloc resection of a portion of the mandible containing the titanium or the biodegradable mesh was then preformed using a reciprocating saw (Figure 5). The titanium was found to be covered by bone in various areas. The titanium mesh was removed by sectioning the mesh using a 702 bur with copious irrigation and by gently peeling the mesh off the bone with a \#9 periosteial elevator (Figure 6). A small amount of soft tissue was tenaciously attached to upper half of the titanium chamber. Due to the difficulty that was encountered when dissecting this soft tissue from the chamber, the soft tissue was discarded with the titanium chamber.

No separation between the new bone graft and the native bone was encountered. On the other hand, the biodegradable mesh was found to have lost its physical strength and was partially resorbed (Figure 10). The residual biodegradable material was gently removed from the underlying bone graft. No damage to the underlying bone was noticed. For both groups the specimens were immediately placed in tubes containing $4 \%$ formaldehyde. The tubes were clearly marked with, the name and number of the rabbit, the mesh type and the area of the mandible where the bone graft was placed (ramus vs. body). All specimens were transported to the JTN Wong Labs (Centre for Bone and Periodontal Research, McGill University, Montréal, $Q C$ ) on the same day for further processing. 

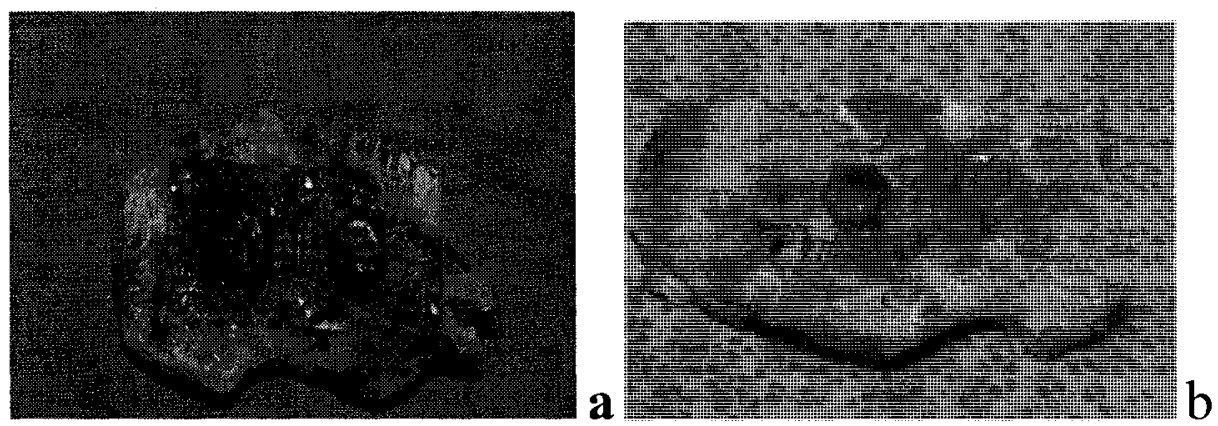

Figure 5. Post-mortem specimen showing, Ti (a) \& PLA (b) meshes

\subsubsection{Micro-CT analysis}

All samples were scanned using a standard desktop micro-CT instrument (Model 1072, Skyscan, Aartselaar, Belgium). The scanner was configured at $100 \mathrm{kV}$ and at $98 \mu \mathrm{A}$. The CT scan Images were captured using a 12-bit, cooled CCD camera (1024 X 1024 pixels) coupled with a fiber optics taper to the scintillator. The images were then magnified to a $10.94 \mu \mathrm{m}$ pixel size. Images were sectioned perpendicular to the native bone with a $21.88 \mu \mathrm{m}$ distance between each cross-section. Each cross-section was reduced to half its size in order to facilitate the analysis, given a voxel size of $21.88 \times 21.88 \times 21.88 \mu \mathrm{m} 3$. Next, the images were viewed using Cone-Beam Reconstruction Software (SkyScan. Kontich, Belgium). A 3D rendering model was created (Figure 7, Figure 11) for all specimens using the 3D Creator and CT-Analyzer software (SkyScan, Kontich, Belgium).

Total calcified tissue volume and percentage of bone:

The micro-CT analysis was performed at the Centre for Bone and Periodontal Research, McGill University. The total calcified tissue volume is defined as the total calcified tissue volume that is maintained under both titanium and the biodegradable mesh at 8 weeks post grafting. This volume was measured using the 3D Creator software (SkyScan, Kontich, Belgium).: on a sequence of two-dimensional images from each sample, the area of the bone and marrow was determined and the software generated a $3 \mathrm{D}$ rendering 
model (Figure 7 , Figure 11). A CT-analyzer software (SkyScan, Kontich, Belgium) was used to calculate the volume of this 3D rendering model which represent the total volume (in $\mathrm{mm} 3$ ) of calcified tissue found under the chambers .

\subsubsection{Histologic preparation and assessment}

The specimens were fixed with $4 \%$ formaldehyde and sequentially embedding in Polymethylmethacrylate (PMMA) following the protocol in appendix IV. The histological preparations and the histomorphometric analyses were preformed the J.T.N Wong Labs (Centre for bone and periodontal research, McGill University, Montréal, QC). Histological preparations were preformed for 22 out of 24 specimens. The remaining two specimens were damaged during histological preparation and / or the embedding procedure.

\section{Histological sectioning and staining}

Using a microtome the graft bone blocks were sectioned to produce a 4-5 um thick slices. The sections are produced in a sagital cross section plane through the center of each specimen. These sections are also perpendicular to the outer cortex of the mandible. Two representative sections from the centre of the specimen were chosen and mounted on slides. After deplastification using ethylene glycol, monoethyl ether and acetate respectively for 30 minutes each, the staining was applied. The staining was done according to a standardized protocol (see Appendices IV). An image of the histological slides that were stained with Von kossa and Toluidine blue was captured using a digital camera connected to a light microscope at $2.5 \mathrm{x}$ magnification (Figure 8 \& Figure 12).

Histomorphometric analysis:

Image-J software (version 1.37v) was used to conduct the histomnorphometric analysis. The histological slide image was captured and 
analyzed. The software was calibrated so that 245.65 pixels equaled $1 \mathrm{~mm}$. The total calcified tissue was shaded and the particle analyzer feature in the software was used to calculate the total surface area of calcified tissue within each group (Ti and PLA groups). An identical procedure was performed to calculate the amount of calcified tissue surface area in the upper and lower parts of the chambers in both groups (Figure $9 \&$ Figure 13). Thereafter, the calcified tissue surface area and distribution (i.e. the amount of calcified tissue in the upper versus the lower half of the chamber) were evaluated. 


\section{CHAPTER THREE \\ RESULTS}

\subsubsection{CLINICAL COURSE}

All of the 12 animals were sacrificed 8 weeks after surgery as per the experiment protocol. None of these animals had an infection at the recipient site. However three animals had a non-infected open wound at the donor sites which healed without complications. All of the animals resumed their regular diet on time. No animals had to be sacrificed due to weight loss.

\subsubsection{THE TITANIUM GROUP( CONTROL)}

\subsubsection{Gross description:}

Post-mortem, all the titanium meshes were found to be covered by a connective tissue capsule. All titanium meshes we found to be stable. No loose mesh or screws were found. The mesh was uneventfully separated from the underlying bone graft. The bone graft under the chamber seemed to be maintaining its original volume. A small amount of soft tissue was tenaciously attached to upper half of the titanium chamber. No separation between the new bone graft and the native bone was noticed (Figure 6)
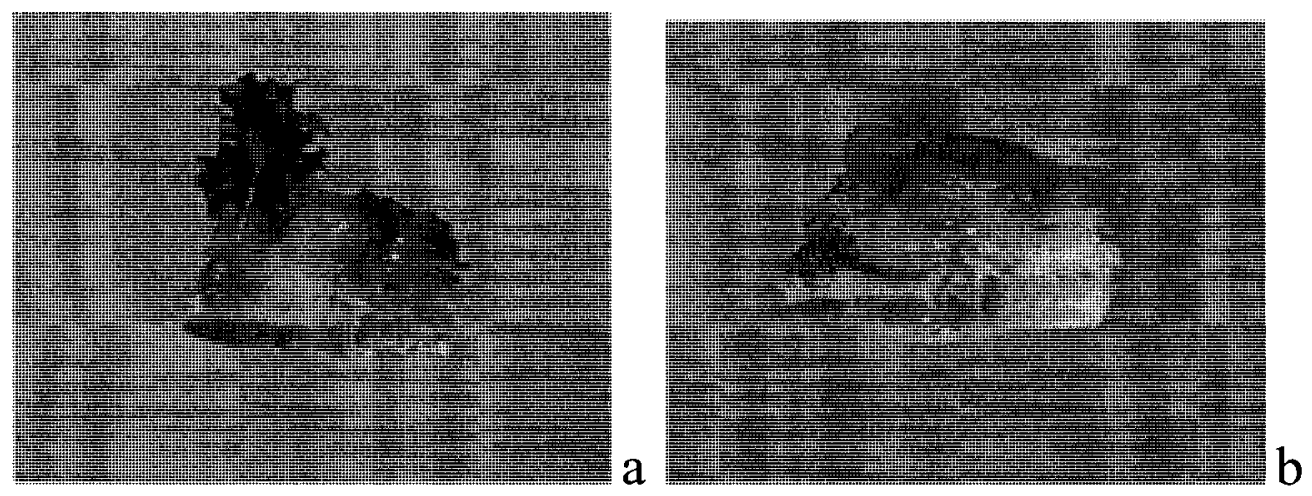

Figure 6. Specimen during removal of Ti mesh (a) \& post removal of the Ti mesh showing maintenance of bone graft volume (b) 


\subsubsection{Micro-CT analysis}

A total of 12 out 12 bone specimens were analyzed (two specimens/ animal) for the total volume of calcified tissue and percentage of bone present under the Ti chamber.

All statistical calculations in this study were preformed using "Graph pad software" (Online Calculator, GraphPad Software, Inc., San Diego, USA). An unpaired t- test was preformed to compare the means of both groups. The mean, standard deviations and sample size for both groups were entered; and next a $P$-value was generated.

(http://www.graphpad.com/quickcalcs/ttest1.cfm?Format=SD)

In the $\mathrm{Ti}$ mesh group there was no statistically significant difference between the $\mathrm{Ti}$ subgroups (i.e. the ramus and the body) with regards to calcified tissue volume and the percentage of bone under the chamber $(P$ value $=0.6131)$. Therefore, the variable "location" was removed and the two groups were pooled together to increase the statistical power. The mean volume of calcified tissue for each Ti subgroup at 8 weeks is presented in Table 1. The volume of calcified tissue and percentage of bone was calculated for each specimen (see Appendices V).

\begin{tabular}{|c|c|c|}
\hline Group & $\begin{array}{l}\text { Calcified tissue } \\
\text { volume }(\mathrm{mm})\end{array}$ & $\begin{array}{l}\text { Percentigge of } \\
\text { Bone }\end{array}$ \\
\hline 2.te 11 bod & 7.31 & 14.36 \\
\hline (2) Thromist & 7.96 & 15.65 \\
\hline
\end{tabular}

Table 1. Volume of calcified tissue means $\left(\mathrm{mm}^{3}\right)$ and percentage of bone $(\%)$ 


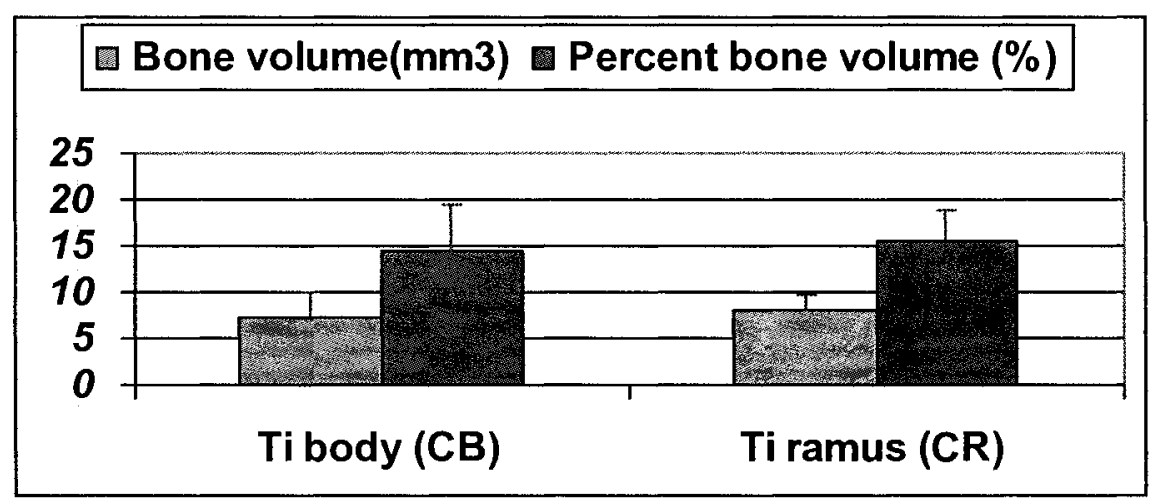

Graph 1. Micro CT volumetric analysis for both Ti subgroups
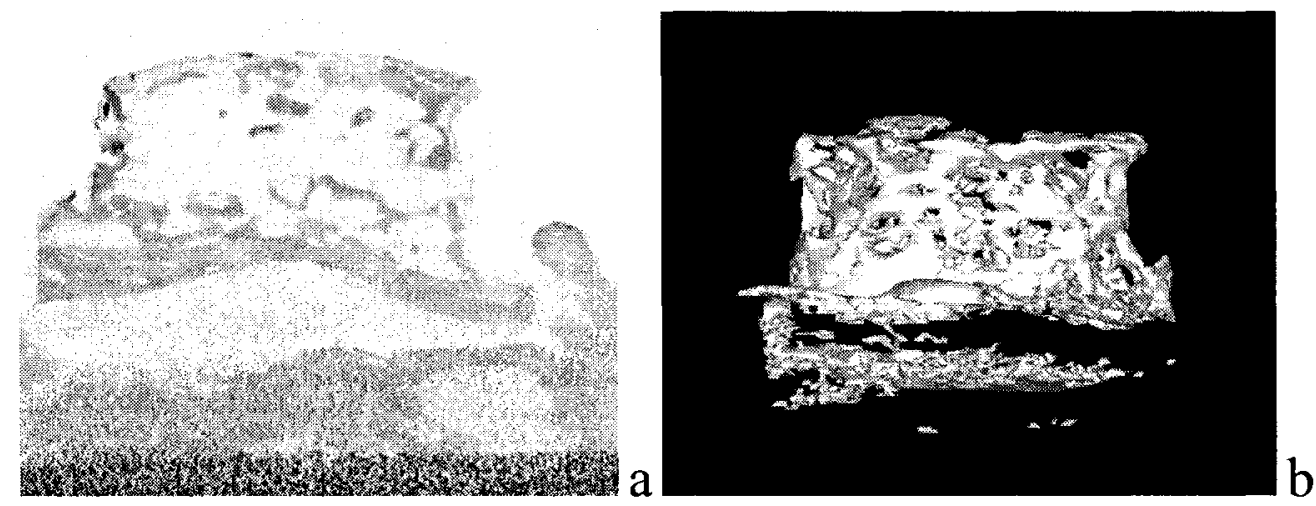

Figure 7. Micro CT sagital cross section from the center of Ti specimen (a) $\& 3 \mathrm{D}$ rendering model (b).

\subsubsection{Histologic description}

Only 10 out of 12 specimens were available for histological analyses. The remaining two specimens were damaged during histological preparation and /or the embedding procedure.

Specimens were viewed under a light microscope $(2.5 \quad X$ magnifications) the bone growth pattern in this group showed adherence of new forming bone to the titanium chamber walls (Figure8). The calcified tissue appeared to be evenly distributed throughout the titanium chamber in both stains (i.e. Von Kossa \& Toluidine Blue) 

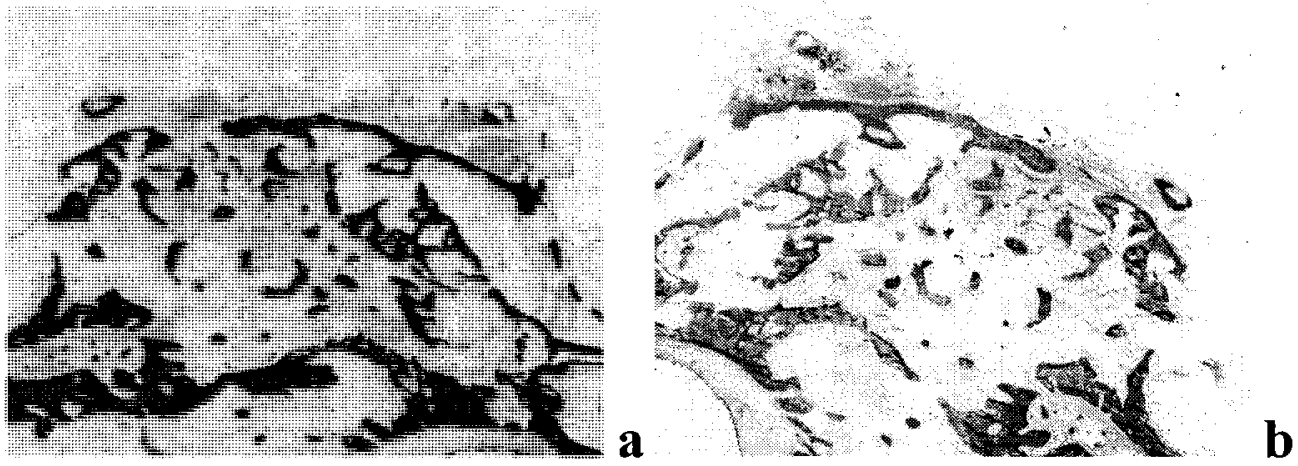

Figure 8. Histologic slide of Ti specimen (2.5X magnification) stained with Von Kossa (a) \& Toluidine Blue (b)

\subsubsection{Histomorphometric Analysis}

The total Calcified tissue surface area

There was no significant statistical difference $(P$-value $=0.0523)$ between the Ti subgroups (i.e. Ramus and body), with regard to mineralized tissue surface area and percentage of bone in the central cut through the specimen. Therefore, the variable "location" was eliminated and the two groups were pooled together to increase the statistical power. A summary of the results of the histomorphometric analysis is presented in Table 2. More detailed descriptions of the results are found in Appendices VI.

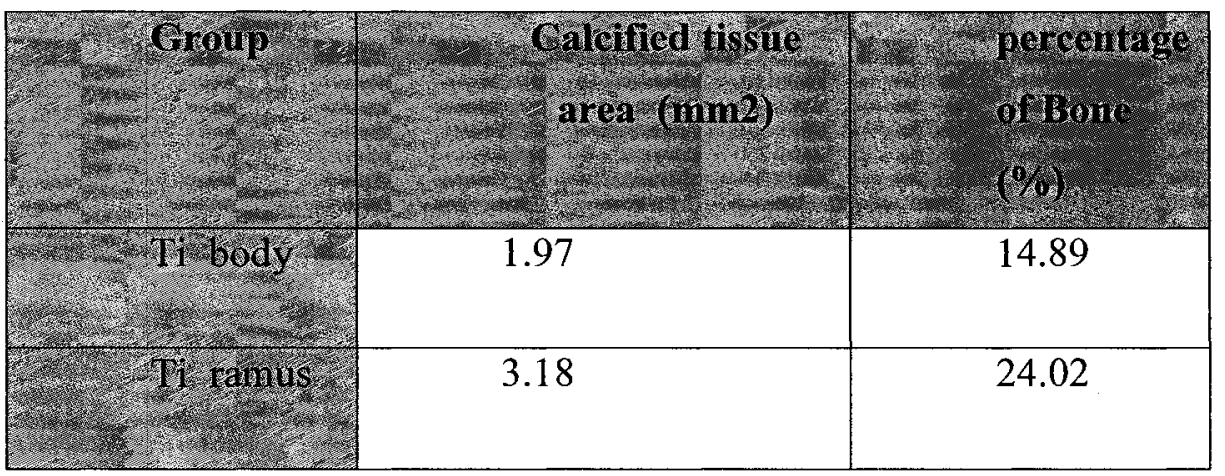

Table 2. Calcified tissue surface area means $\left(\mathrm{mm}^{2}\right)$ and percentage of bone $(\%)$ 
Distribution of calcified tissue under the Ti chamber

In the Ti subgroups (i.e. Ramus and body), with regard to distribution of calcified tissue in the central cut through the specimen, there was no significant, statistical difference when comparing the lower half $(P$-value $=$ $0.2446)$ and the upper half $(P$-value $=0.2535)$ of the chamber between the two $\mathrm{Ti}$ subgroups. A summary of the results of the histomorphometric analysis is presented in Table 3. More detailed descriptions of the results are found in Appendices VI.

\begin{tabular}{|c|c|c|c|}
\hline Gromp & $\begin{array}{c}\text { Whocr } \\
\text { hair } \\
\text { bone } \%\end{array}$ & 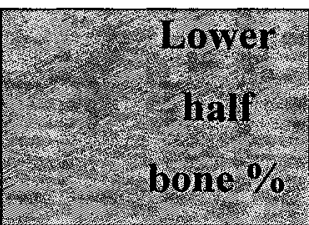 & (5) \\
\hline Ti body & 5.77 & 9.12 & 14.89 \\
\hline Tirrams & 10.82 & 13.20 & 24.02 \\
\hline
\end{tabular}

Table 3. Distribution of calcified tissue in a sagital cross section through the center of the Ti specimen by location

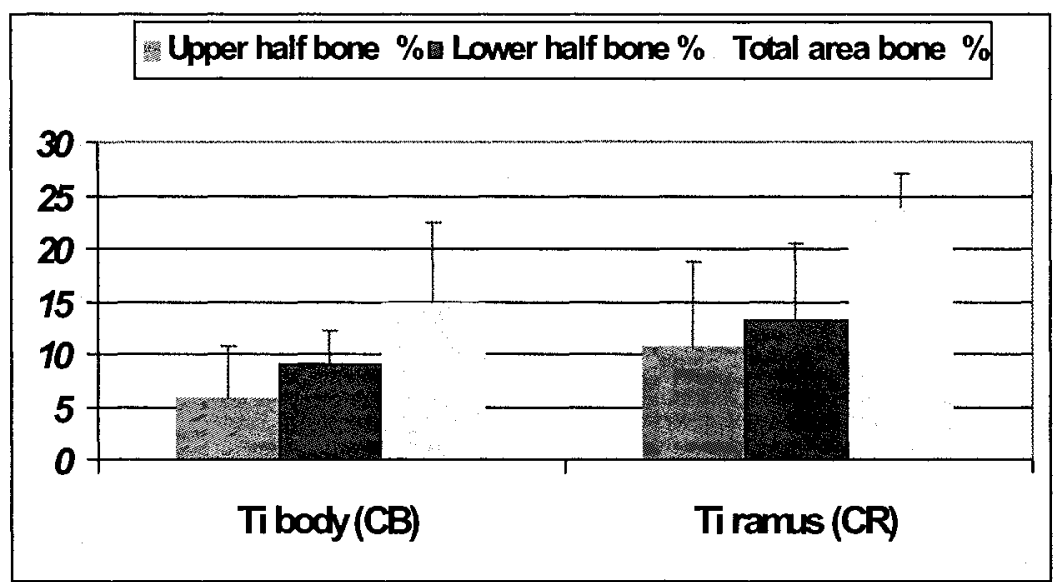

Graph 2. Distribution of calcified tissue in a sagital cross section Through the center of the Ti specimen by location 


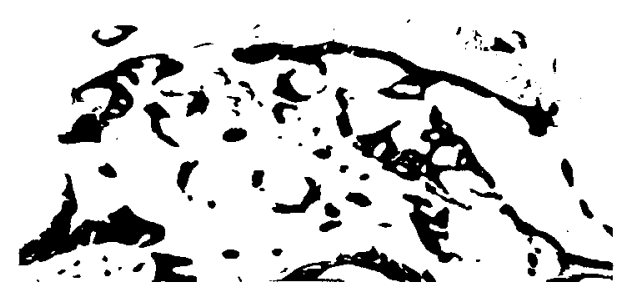

Figure 9, Image generated by "Image J" software used for histomorphometric analysis in $\mathrm{Ti}$ group.

\subsubsection{THE BIODEGRADABLE GROUP (Test):}

\subsubsection{Gross description:}

Post-mortem, all the biodegradable meshes were found to be covered by a connective tissue capsule. All the biodgradable meshes and tacks were found to have lost their physical characteristics (i.e. strength) and to have undergone partial degradation with a variable amount of residual biodegradable material scattered on the bone graft. A variable amount of bone was found beyond the chambers in the areas that were previously occupied by the mesh (Figure 10).
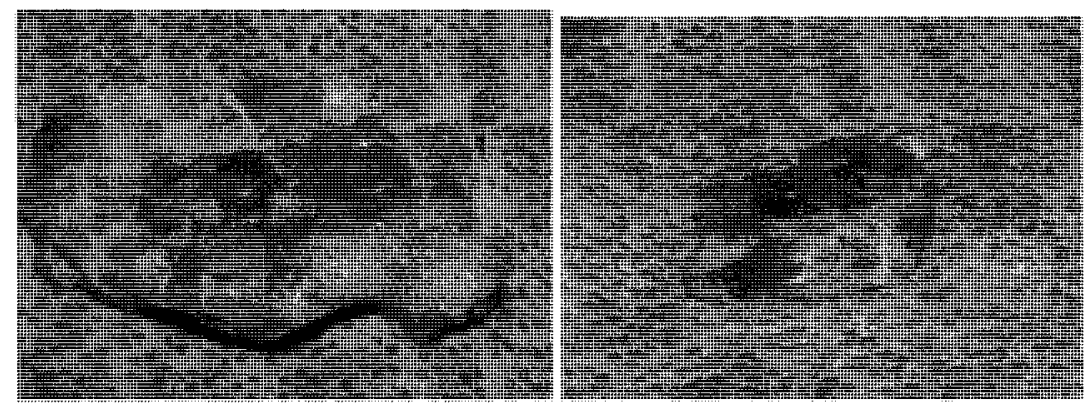

Figure 10. Post-mortem specimen, showing partial degradation

of PLA mesh. 


\subsubsection{MICRO-CT ANALYSES}

A total of 12 out 12 bone specimens were analyzed (two specimens/ animal) for the total volume of calcified tissue and percentage of bone present under the Ti chamber.

In the PLA sub-groups (i.e. ramus and body) there was no significant statistical difference between both subgroups with regard to the volume of calcified tissue and the percentage of bone $(P$ value $=0.0554)$. The mean volume of calcified tissue for each group at 8 weeks is presented in Table 4. The volume of calcified tissue and percentage of bone was calculated for each specimen (see Appendices $V$ )

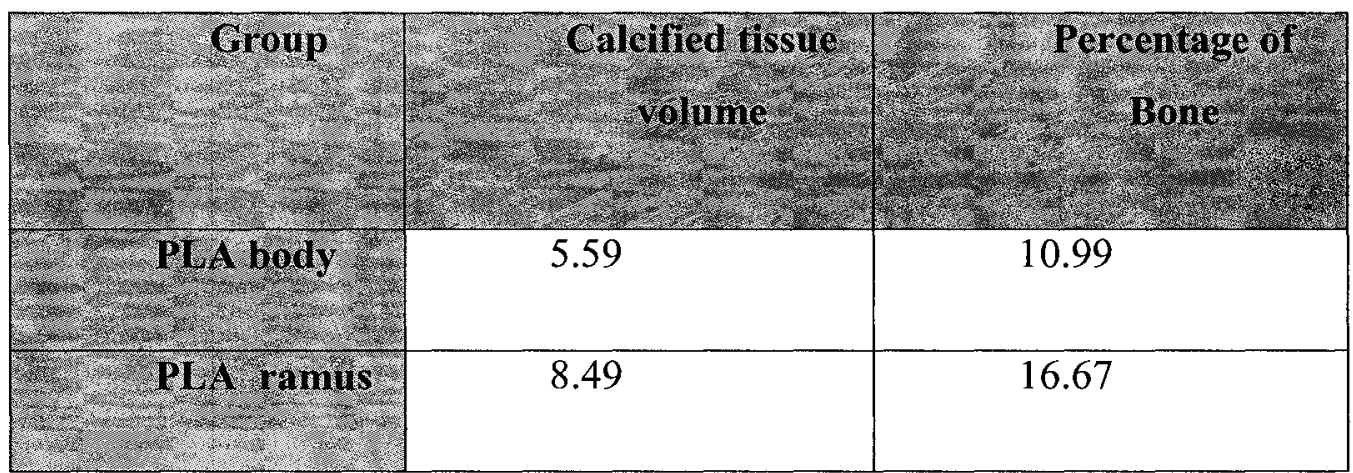

Table 4 .Volume of calcified tissue means $\left(\mathrm{mm}^{3}\right)$ and percentage of bone $(\%)$

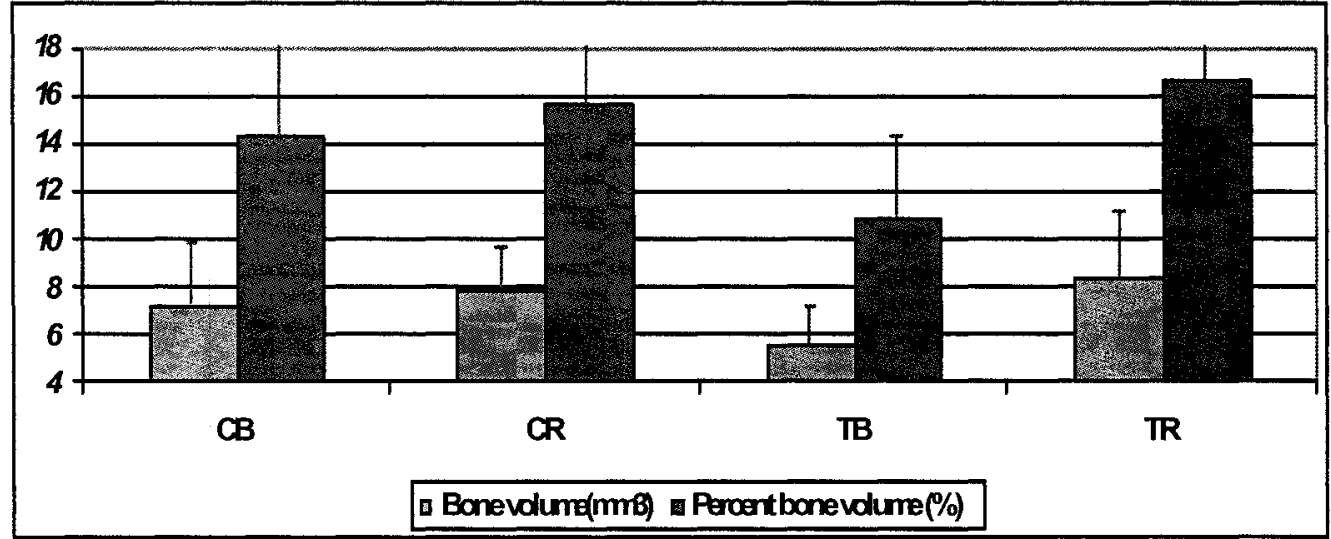

Graph 3. Volume of calcified tissue means $\left(\mathrm{mm}^{3}\right)$ and percentage of bone $(\%)$ 

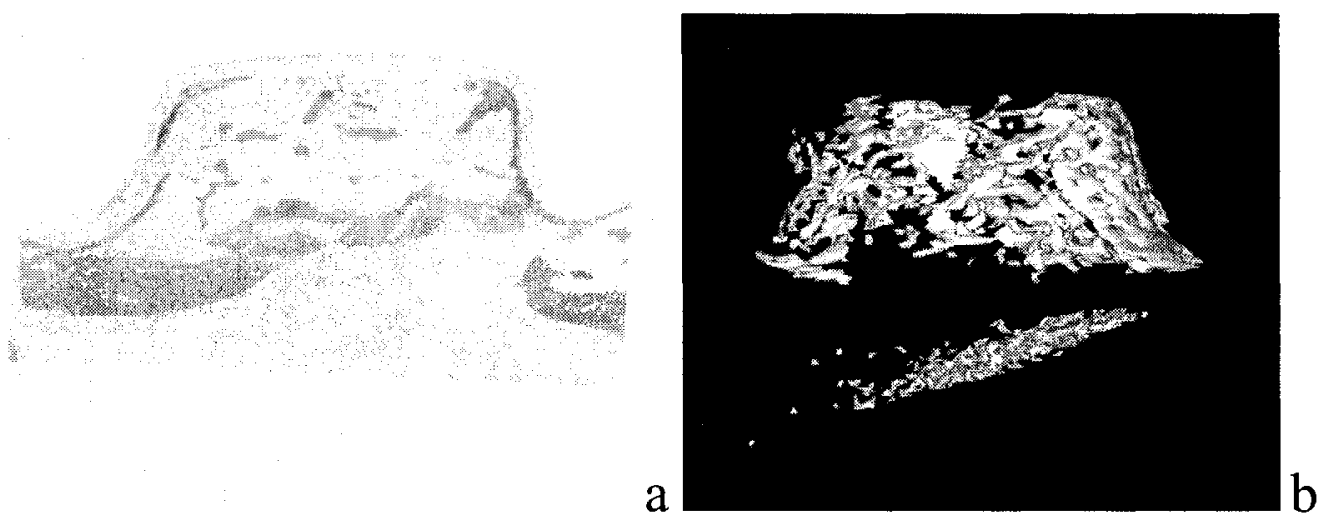

Figure 11. Micro CT sagital cut from the center of a PLA specimen (a) \& 3D rendering model (b).

\subsubsection{Histologic description:}

When specimens were viewed under the light microscope $(2.5 X$ magnifications) the bone growth pattern in this group showed adherence of the new forming bone to the biodegradable mesh chamber walls (Figure 12). The calcified tissue seemed to be evenly distributed under the chamber.

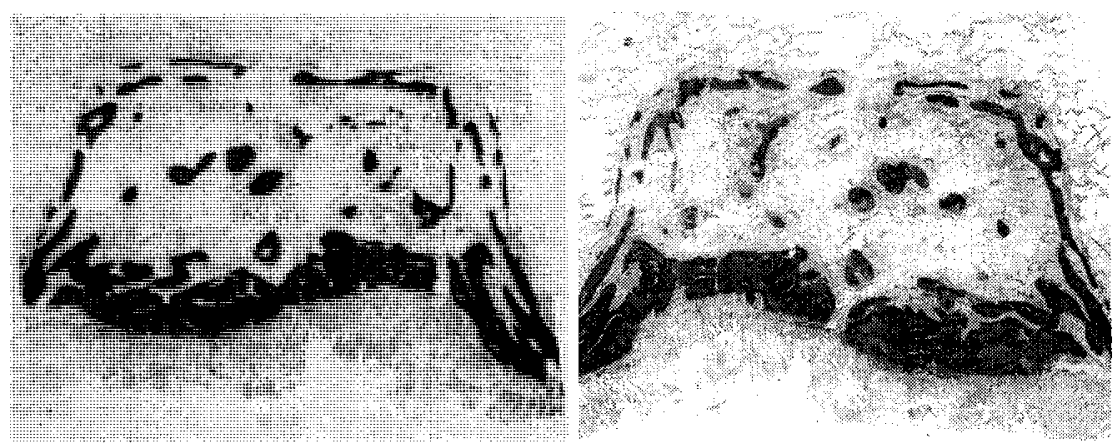

Figure 12. Histologic slide of PLA specimen (2.5X magnification) stained with Von Kossa (a) \& Toluidine Blue (b) 


\subsubsection{Histomorphometric description:}

A total of 12 out of 12 specimens were available for histological analyses for the following parameters.

Total Calcified tissue surface area

In the biodegradable subgroups (i.e. ramus and body) with regard to mineralized tissue surface area and the percentage of bone we found no significant statistical difference when both groups were compared $(P$-value $=$ 0.5082). Therefore, the variable "location" was eliminated and the two groups were pooled together to increase the statistical power. A summary of the results of the histomorphometric analysis is presented in Tables 5. More detailed descriptions of the results are found in Appendices VI.

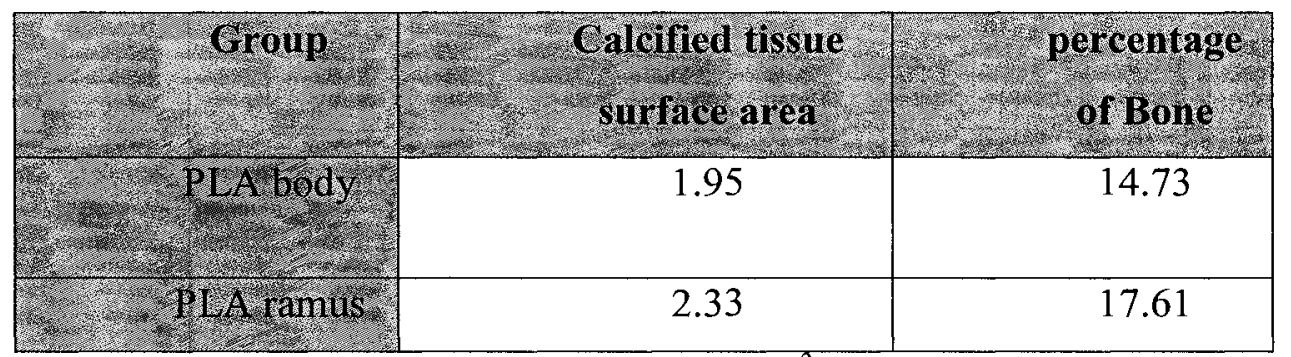

Table 5.Calcified tissue surface area means $\left(\mathrm{mm}^{2}\right) \&$ percentage of bone $(\%)$ in PLA subgroups

Distribution of calcified tissue under the biodegradable mesh chambers

In the biodegradable subgroups (i.e. ramus and body) the distribution of calcified tissue under the chamber was recorded. There was no significant statistical difference when comparing the calcified tissue area and percentage of bone in the lower half $(P$-value $=0.402)$ and the upper half $(P$-value $=$ 0.9481) of the chamber between the two biodegradable subgroups. A summary of the results of the histomorphometric analysis are presented in Table 6. More detailed descriptions of the results are found in Appendices VI 


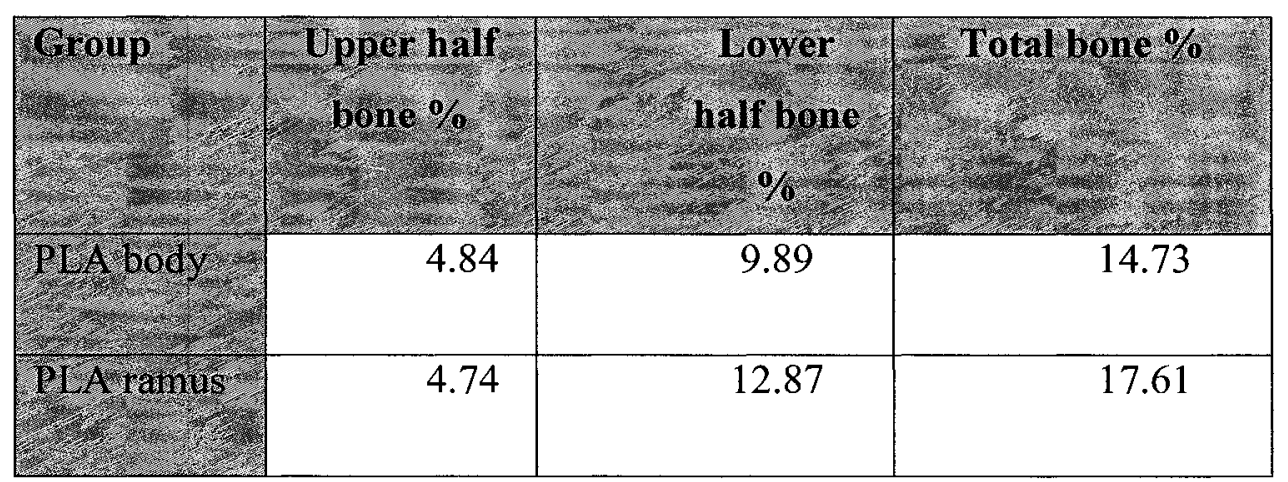

Table 6. Distribution of calcified tissue in a sagital cross section through the center of PLA specimen by location

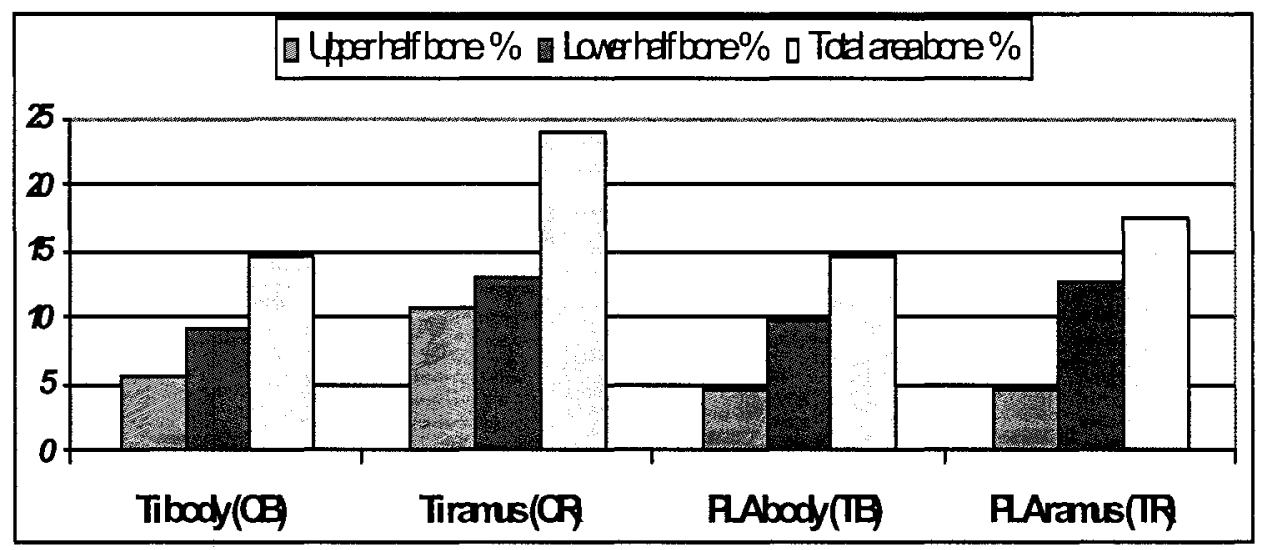

Graph 4. Distribution of calcified tissue in a sagital cross section through the center of both Ti \& PLA specimens by location

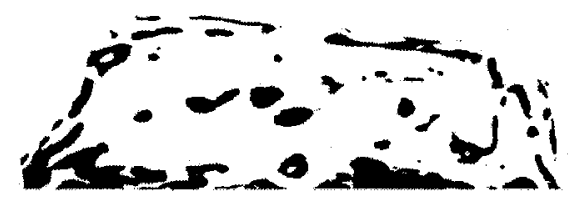

Figure 13. Image generated by "Image J" software used for histomorphometric analysis in PLA group. 


\subsubsection{COMPARING TITANIUM AND BIODEGRADABLE GROUPS}

\subsubsection{Micro-Ct analysis}

A total of 24 of 24 bone specimens were analyzed (two specimens/ animal) for the total volume of calcified tissue and the percentage of bone. When comparing the pooled data from the titanium mesh and the biodegradable mesh groups, no significant statistical difference was found with regard to the calcified tissue volume and the percentage of bone under the chamber $(P-$ value $=0.546)$

The mean volume of calcified tissue for each group (i.e. Ti and PLA) at 8 weeks is presented in Table 7. The volume of calcified tissue and percentage of bone was calculated for each specimen (see Appendices $V$ )

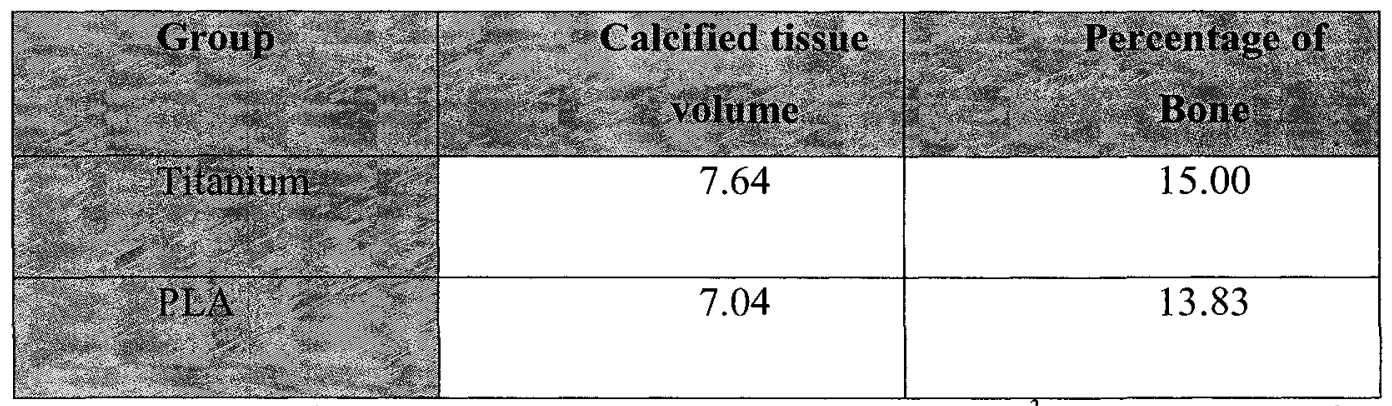

Table 7: Pooled values, volume of calcified tissue means $\left(\mathrm{mm}^{3}\right)$ and percentage of bone (\%) for both groups(Ti \&PLA)

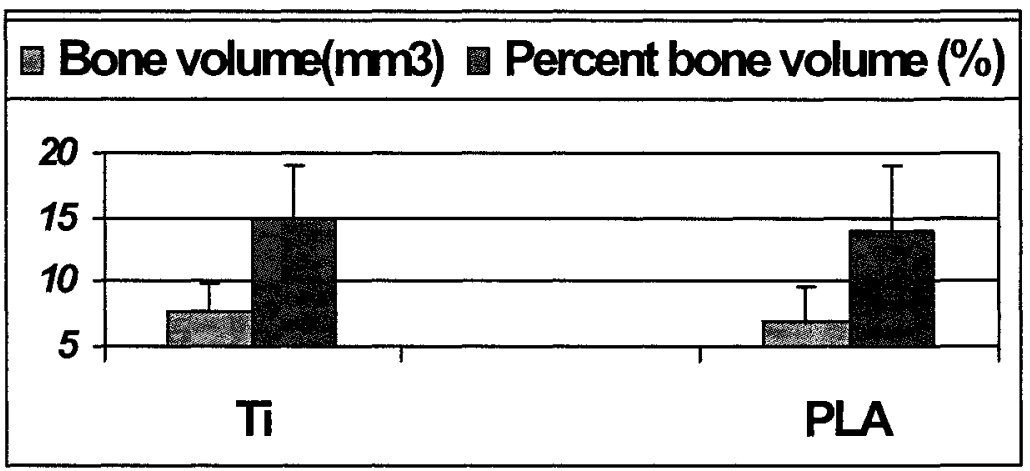

Graph 5. Pooled values, volume of calcified tissue means $\left(\mathrm{mm}^{3}\right)$ and percentage of bone (\%) for both groups (Ti \&PLA) 


\subsubsection{Histomorphometric description:}

A total of 22 out of 24 specimens were available for histological analysis. The remaining two specimens were damaged during histological preparation and/or the embedding procedure.

\section{Total Calcified tissue surface area}

When the pooled data from the two groups (i.e. Ti and PLA) were compared with regard to mineralized tissue surface area and the percentage of bone, no significant statistical difference was found $(P$-value $=0.8272)$. A summary of the results of the histomorphometric analysis are presented in Tables 8. Detailed descriptions of the results are found in Appendices VI.

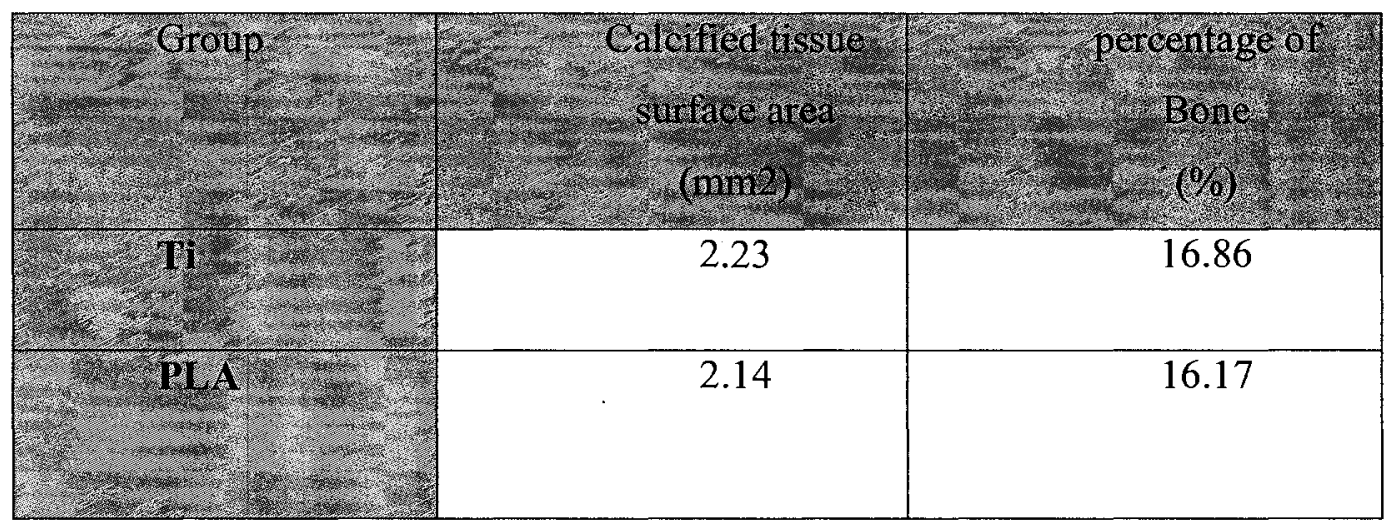

Table 8. Pooled values of calcified tissue in a sagital cross section Through the center of specimens for both groups (Ti \& PLA) 


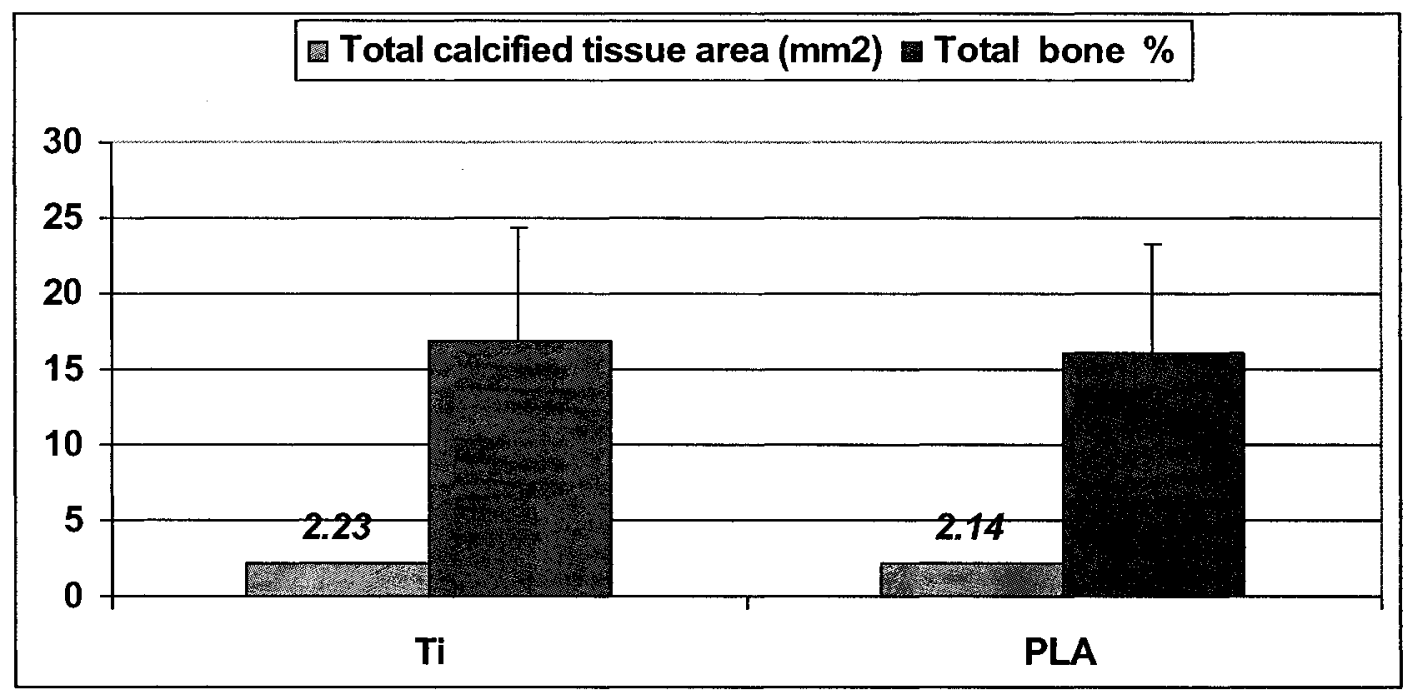

Graph 6. Pooled values of calcified tissue in a sagital cross section Through the center of specimens for both groups (Ti \& PLA)

\section{Distribution of calcified tissue under both groups}

The pooled data of both groups were compared (i.e. Ti and PLA) with regard to distribution of calcified tissue in the center cross section of the specimen. There was no significant statistical difference when comparing the calcified tissue area and percentage of bone in the lower half ( $P$-value $=$ $0.5059)$ and the upper half $(P$-value $=0.1561)$ of the chamber between the two groups. A summary of the results of the histomorphometric analysis is presented in Tables 9. More detailed descriptions of the results are found in Appendices VI.

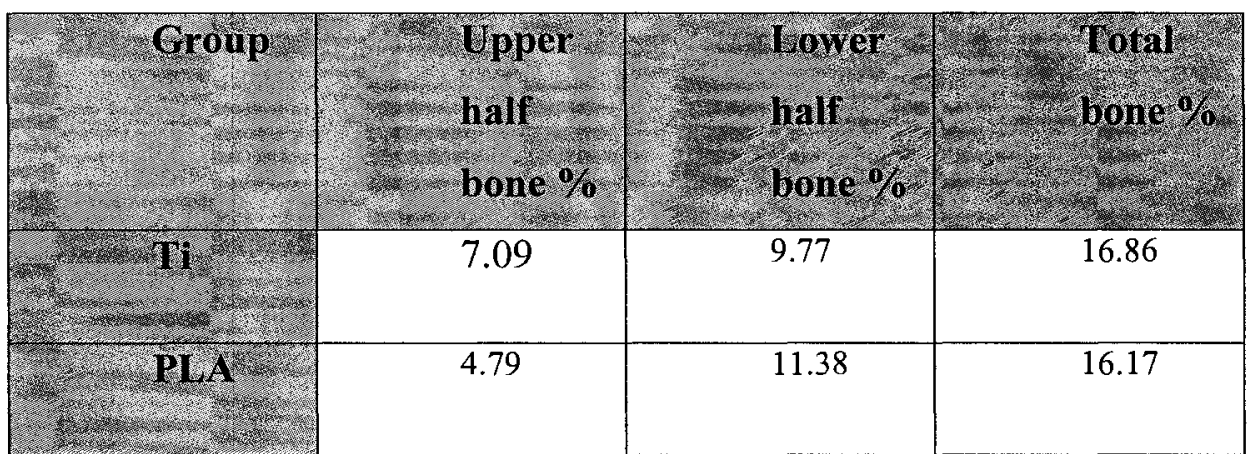

Table 9. Pooled values of distribution of calcified tissue in a sagital cross section Through the center of specimens for both groups (Ti \& PLA) 


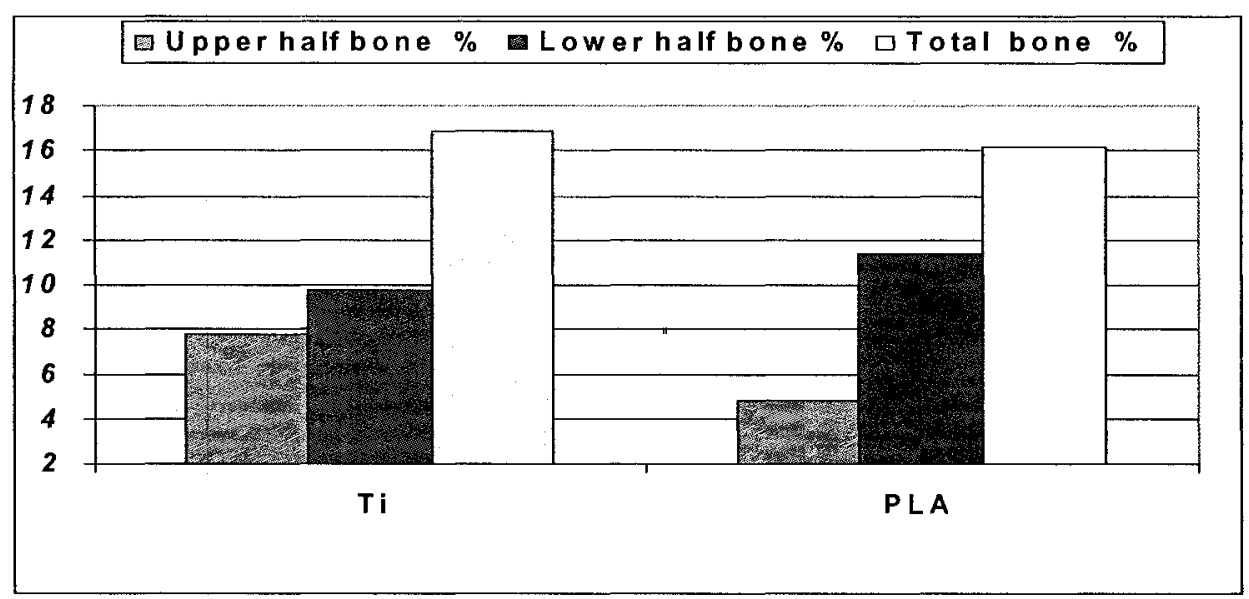

Graph 6. Pooled values of distribution of calcified tissue in a sagital cross section Through the center of specimens for both groups (Ti \& PLA) 


\section{CHAPTER FOUR \\ DISCUSSION}

\subsubsection{TEST GROUP (PLA MESH)}

In clinical trials, PBCM has been shown to be an excellent bone graft material for jaw reconstruction (Marx et al 1993, 2002). PBCM bone grafts have the advantage of early revascularization (Albrektsson et al. 1980; Burchardt et. al. 1983) and enhanced osteogenic potential (Gray et. al. 1972) compared to other types of autogenic bone graft materials. The literature advocates the use of the titanium mesh fixation device for PBCM bone graft support (Von Arx et. al. 1996, 1998, 1999; El-Hakim, 2006).However, the major disadvantage is that the mesh needs to be removed prior to, or at the time of dental implant placement. This therefore lengthens the surgical procedure and exposes the patient to a more extensive surgery.

The results of this experiment indicate that resorbable mesh composed of copolymers (PLA/PGA) is an ideal substitute for the Ti mesh as a fixation device for the support of onlay PBCM bone grafts for the reconstruction of alveolar bone defects. In this experiment there was no significant statistical deference between these groups $(\mathrm{P}-$ value $=0.546)$ with regard to the percentage of bone found under this mesh. The percentage bone volume formed under the PLA mesh was found to be $13.83 \%$ compared to $15 \%$ under the Ti mesh group (control group).

Studies on the use of PLA membrane to support an onlay PBCM bone graft are still lacking in the literature. This made comparing the results of this experiment to those of other studies difficult. The closest studies available are those of Kinoshita et al (1997) and Eppley et al. (1997) both of which used PBCM bone grafts as an inlay. In their study, Kinoshita et al (1997) used a canine model to evaluate the healing of a continuity defect in the mandible using a PLA mesh tray and PBCM graft. The author reported complete 
healing of the bony defects, producing well shaped alveolar ridges. In a rabbit model, Eppley and Colleagues (1997) evaluated the healing of calvarial inlay corticocancellous blocks, fixed with either titanium or biodegradable mesh made of a copolymer (PLA/PLG). Both groups showed complete healing with no evidence of inflammation. The results of both studies are in agreement with the findings of this experiment, confirming that PLA mesh is an efficient device for GBR procedures.

According to the manufacturer (Inion GTR ${ }^{\mathrm{TM}}$, Finland), this material will biodegrade by enzymatic hydrolysis. The material will start to lose its physical properties in 2-4 months after implantation and will completely degrade by 12 months. This property allows the mesh to withstand the physical load during the critical phases of bone graft healing. In this study, after 2 months of healing, all the biodegradable meshes and tacks were found to have lost their physical characteristics (i.e. strength) and had undergone partial degradation. Therefore, these findings are consistent with the manufacturer's claims. In an in-vitro study the biodegradable material (Inion $G T R^{\mathrm{TM}}$, Finland) was found to start loosing its physical properties from 2- 4 months (Nieminen et al. 2006). These findings are consistent with this experiment with regard to mesh degradation. In this study, the meshes were in fact heat-molded and thus it appears that the specific heating temperature used to mold the mesh did not affect this material's physical properties. Hence, the material has maintained its function.

This study adds more evidence to the literature regarding the osteoconductivity of copolymer (PLA/PGA) material. The histological assessment shows evidence of new bone formation that is adherent to the biodegradable mesh. Similar results were found by Imbronito et al. (2005) as they evaluated the healing pattern of bone defects filled with a copolymer (PLA/PGA) as a filler material in a rabbit tibia model. Bone formation took place concomitantly with the degradation of biodegradable material. Based 
on this finding, the authors claimed that the PLA/PGA material is osteoconductive.

Although there were no soft tissue specimens in this experiment, the histologic examination of the hard tissue specimens indicates the absence of any inflammatory reaction. Also in this experimental study, all animals healed without any recipient site complications, and these findings are consistent with other studies in the literature where bone grafts underneath copolymer (PLA/PGA) meshes healed without any evidence of inflammation or foreign body reaction (Kinoshita Y et al. 1993, 1997). Another experimental study by Nieminen et al (2006), used the sheep model to assess biodegradation of the mesh (Inion GTR ${ }^{\mathrm{TM}}$, Finland) that was implanted on the lateral aspect of the mandible. The author found the mesh present and surrounded by a fibrous connective tissue capsule at 6 and 26 weeks. In addition, foreign body reactions were not observed in any of the specimens. These results are in agreement with findings from this experiment, although, the authors (Nieminen et al, 2006) did not comment on the physical properties nor the outline of the biodegradable mesh at these time points. Their study (Nieminen et al, 2006) is also the only one available in the literature that evaluates the invitro and in-vivo degradation of the biodegradable membrane (Inion $G^{\mathrm{TM}}{ }^{\mathrm{M}}$, Finland). As such, the current experimental study has added valuable information with regards to the degradation of this membrane.

\subsubsection{CONTROL GROUP (Ti MESH)}

In this experimental study the percentage of bone volume that was maintained under the Ti mesh was found to be $15 \%$, and these results are in agreement with the study preformed by El-Hakim (2006). In that study the author used a similar titanium device to what we have used in this experiment, to contain the bone graft. The author (El-Hakim,2006)evaluated volume maintenance for three different types of autogenic bone graft material including an endochondoral cancellous bone graft group. The endochondral 
cancellous bone graft group achieved $10.5 \%$ bone volume in 6 weeks, while in 12 weeks it achieved $23.5 \%$, thus showing an increase of bone volume with time. The results of this current experimental study fall in between the two time periods in that experiment (El-Hakim, 2006). Such results confirm that bone graft maintenance underneath the Ti mesh is predictable.

In another study using a rabbit model, Ozaki and Buchman (1998) applied cancellous endochondral bone grafts on the calvarium of the rabbits, as an onlay graft, without a fixation device. They found that such a bone graft retained $8.1 \%$ of its original volume at 8 weeks and only $2.1 \%$ at 16 weeks. Their results showed a lower percentage of bone volume than what was found in the current experiment $(15 \%)$. In the current experiment the percentage bone volume was almost double that observed by Ozaki and Buchman (1998). The improved percentage of bone volume in the current study is presumed to be due to the fixation of the bone graft, with the titanium mesh.

Moreover, this experiment indicated that the $\mathrm{Ti}$ mesh is an osteoconductive device. Histological assessment showed new bone formation adherent to the Ti mesh and the results of this experiment have also confirmed the biocompatibility of this material, where all animals healed without any complication related to the recipient site. The results derived from the current study are in agreement with those of other studies. Von Arx et. al. (1996, 1998, 1999) published multiple clinical trials advocating the use of microporous titanium mesh to stabilize autogenous bone grafts for the reconstruction of alveolar defects and peri-implant defects. These authors showed complete healing of the bony defects and reported that the excellent results are due to the effect of the $\mathrm{Ti}$ mesh. The $\mathrm{Ti}$ mesh thus provided excellent tissue compatibility, geometric stability and little clinical and histological inflammation when the mesh was exposed 


\subsubsection{CONCLUSION AND RECOMMENDATIONS}

This study confirms that bone graft maintenance underneath Ti mesh is predictable. It was also demonstrated that biodegradable mesh composed of copolymers (PLA/PGA) is an ideal substitute for the Ti mesh as a fixation device for the support of onlay PBCM bone grafts for the reconstruction of alveolar bone defects. The resorbable mesh has been shown to have adequate physical properties for the support of $\mathrm{PBCM}$ bone graft as an onlay. The copolymer (PLA/PGA) material showed excellent volume maintenance of bone .In the current experimental study the biodegradation of the PLA/PGA material with no inflammation was observed. This material starts to lose its physical properties by 2 months and is completely degraded by 12 months. Therefore, using a PLA mesh offers the advantage of not requiring removal prior to or at the time of implant placement, thus exposing the patient to a less extensive surgery. Given all stated advantage, the PLA mesh can be considered for further clinical trails. 


\section{Appendix I}

\section{Randomization of animals, surgery dates, and sacrifice dates}

\begin{tabular}{|c|c|c|c|c|}
\hline Name & Animal \# & $\begin{array}{l}\text { Type of } \\
\text { implant }\end{array}$ & Date of surgery & Date of sacrifice \\
\hline Laurier & $\begin{array}{l}\text { CB63025 } \\
\text { CR63025 }\end{array}$ & $\mathrm{Ti}$ & $10 / 10 / 2006$ & $6 / 12 / 2006$ \\
\hline Jarry & $\begin{array}{l}\text { CB63028 } \\
\text { CR63028 }\end{array}$ & $\overline{\mathrm{Ti}}$ & $11 / 10 / 2006$ & $6 / 12 / 2006$ \\
\hline Beaubien & $\begin{array}{l}\text { CB63027 } \\
\text { CR63027 }\end{array}$ & $\mathrm{Ti}$ & $11 / 10 / 2006$ & $6 / 12 / 2006$ \\
\hline Mcgill & $\begin{array}{l}\text { CB63040 } \\
\text { CR63040 }\end{array}$ & $\mathrm{Ti}$ & $13 / 10 / 2006$ & $8 / 12 / 2006$ \\
\hline Saint-Laurent & $\begin{array}{l}\text { TB63042 } \\
\text { TR63042 }\end{array}$ & PLA & $17 / 10 / 2006$ & $14 / 12 / 2006$ \\
\hline Joliette & $\begin{array}{l}\text { TB63044 } \\
\text { TR63044 }\end{array}$ & PLA & $19 / 10 / 2006$ & $14 / 12 / 2006$ \\
\hline Pie-IX & $\begin{array}{l}\text { TB63046 } \\
\text { TR63046 }\end{array}$ & PLA & $19 / 10 / 2006$ & $14 / 12 / 2006$ \\
\hline Langelier & $\begin{array}{l}\text { TB63038 } \\
\text { TR63038 }\end{array}$ & $\overline{\text { PLA }}$ & $20 / 10 / 2006$ & $14 / 12 / 2006$ \\
\hline Beaudry & $\begin{array}{l}\text { TB63043 } \\
\text { TR63043 }\end{array}$ & PLA & $20 / 10 / 2006$ & $14 / 12 / 2006$ \\
\hline Atwater & $\begin{array}{l}\text { TB63047 } \\
\text { TR63043 }\end{array}$ & PLA & $23 / 10 / 2006$ & $18 / 12 / 2006$ \\
\hline Jolicoeur & $\begin{array}{l}\text { CB63058 } \\
\text { CR63058 }\end{array}$ & $\overline{\mathrm{Ti}}$ & $3 / 11 / 2006$ & $3 / 1 / 2007$ \\
\hline Monk & $\begin{array}{l}\text { CB63057 } \\
\text { CR63057 }\end{array}$ & $\mathrm{Ti}$ & $3 / 11 / 2006$ & $3 / 1 / 2007$ \\
\hline
\end{tabular}




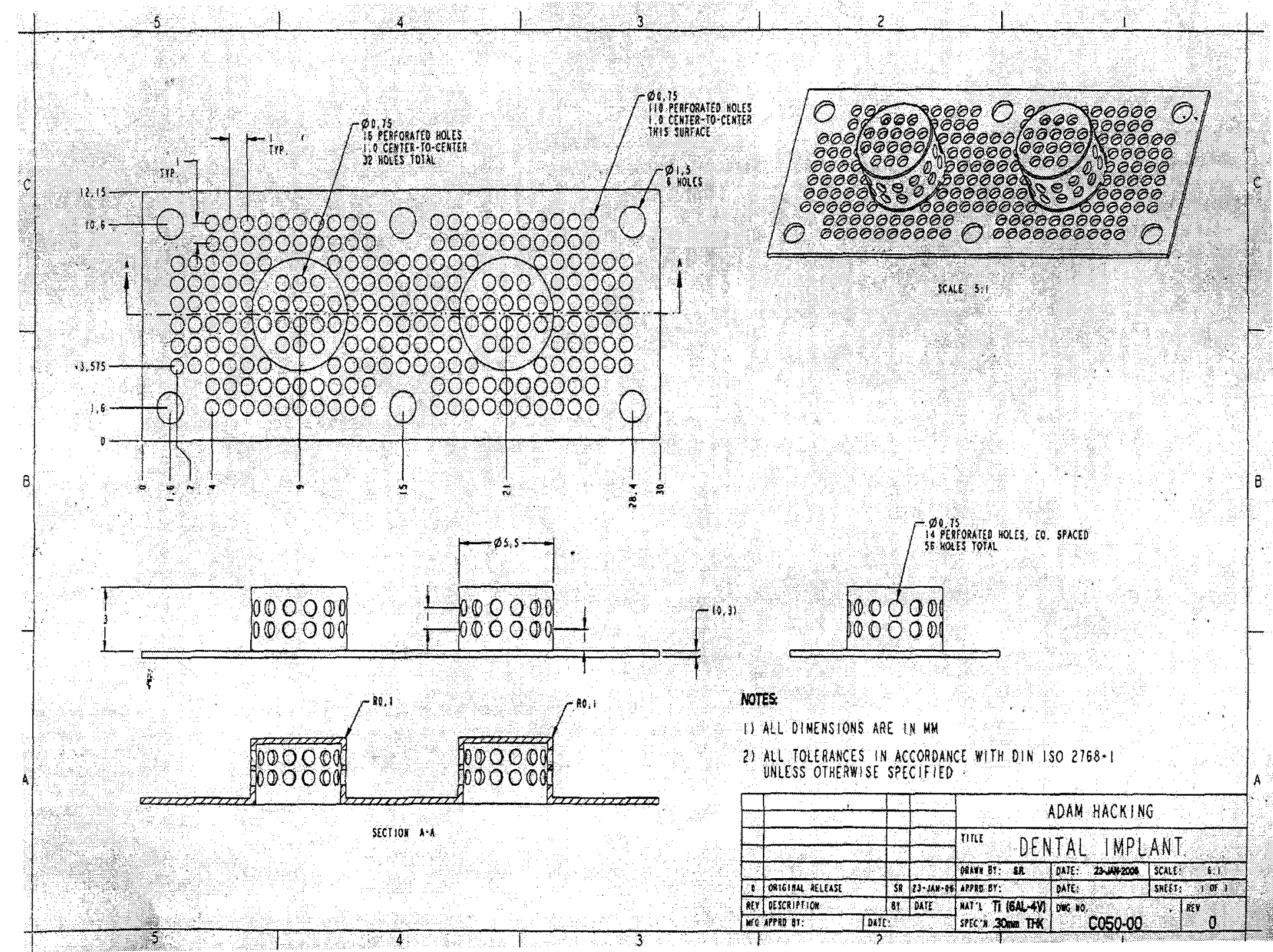

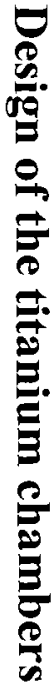




\section{Appendix IV \\ Specimens Preparation and embedding protocol}

\section{Preparation;}

The bone graft specimens were stored sequentially in the following solutions for a minimum of 48 hours:

1- $4 \%$ formaldehyde vol./vol. for fixation.

2- $70 \%$ solution $\mathrm{v} / \mathrm{v}$ of ethanol (Commercial Alcohols Inc., Brampton, on.) and water for drying.

3- $95 \%$ solution $\mathrm{v} / \mathrm{v}$ of ethanol and water for drying.

4- 1:1 solution $\mathrm{v} / \mathrm{v}$ of ether/acetone (JT Baker Inc. Jackson, TN) for degreasing and defatting.

5- Anhydrous ethanol for final drying.

In addition, magnetic stirring at each stage facilitated permeation of each fluid into the bone.

\section{Embedding}

Prior to embedding, all specimens were pre-soaked for a minimum of 48 hours in a solution of Polymethylmethacrylate (PMMA) (Aldrich Chemicals, Oakville, On.) inhibited with $10 \mathrm{ppm}$ hyrdoquinone. The PMMA solution was activated with the addition of $3.5 \mathrm{~g}$ of benzoyl peroxide (Aldrich Chemicals) per liter of PMMA monomer. The specimens in monomer were stored at $4{ }^{\circ} \mathrm{C}$ in a refrigerated environment and magnetically stirred.

All specimens were embedded in PMMA. The process of embedding yielded a sample that was encased in a hard, transparent plastic block. In this manner the specimens were well preserved and mechanically stable for a variety of analysis procedures. The liquid monomer was prepared for polymerization as follows:

1) The inhibited (10 ppm methyl hydroquinone) PMMA monomer was activated with the addition of $3.5 \mathrm{~g}$ of benzoyl peroxide per liter of PMMA monomer. 
2) The activated monomer was heated at $55^{\circ} \mathrm{C}$ in a hot water bath for approximately six hours. During heating the monomer was stirred each $1 / 2$ hour.

3) When the consistency of the partially polymerized solution was similar to thin syrup and slightly yellow in color, the solution was removed from the hot water bath. Upon removal the solution was cooled under tap water and stored at $1^{\circ} \mathrm{C}$. 
Appendix V

Results of the Micro CT

1-Titanium mesh group (Ti)

\begin{tabular}{|c|c|c|c|c|}
\hline Samples & Bone volume(mm3) & SD & Percent bone volume $(\%)$ & SD \\
\hline $\mathrm{CB} 63025$ & 10.94 & & 21.49 & \\
\hline CB 63027 & 8.55 & & 16.81 & \\
\hline$C B \_63028$ & 7.20 & & 14.14 & \\
\hline$C B \quad 63040$ & 3.74 & & 7.35 & \\
\hline$C B \quad 63057$ & 8.22 & & 16.15 & \\
\hline $\mathrm{CB} 63058$ & 5.20 & & 10.22 & \\
\hline Ti body (CB) & 7.31 & 2.56 & 14.36 & 5.03 \\
\hline CR 63025 & 8.72 & & 17.12 & \\
\hline CR 63027 & 5.67 & & 11.13 & \\
\hline CR 63028 & 6.40 & & 12.57 & \\
\hline CR 63040 & 8.16 & & 16.03 & \\
\hline CR 63057 & 10.46 & & 20.54 & \\
\hline CR 63058 & 8.39 & & 16.48 & \\
\hline Ti ramus (CR) & 7.96 & 1.72 & 15.65 & 3.37 \\
\hline
\end{tabular}

\section{2-Resorbable mesh group (PLA)}

$\begin{array}{ccccc}\text { Samples } & \text { Bone volume(mm3) } & \text { SD } & \text { Percent bone volume (\%) } & \text { SD } \\ \text { TB_63038 } & 3.07 & & 6.03 & \\ \text { TB_63042 } & 7.18 & & 14.11 & \\ \text { TB_63043 } & 6.50 & & 12.78 & \\ \text { TB_63044 } & 5.58 & & 10.97 & \\ \text { TB_63046 } & 4.19 & & 13.83 & 3.26 \\ \text { TB_63047 } & 7.04 & & 10.99 & \\ \text { PLA body (TB) } & 5.60 & 1.66 & & \\ & & & & \\ \text { TR_63038 } & 8.41 & & 16.52 & \\ \text { TR_63042 } & 8.88 & & 17.44 & \\ \text { TR_36043 } & 9.87 & & 9.39 & \\ \text { TR_63044 } & 4.82 & & 12.45 & \\ \text { TR_63046 } & 6.34 & & 24.77 & \\ \text { TR_63047 } & 12.61 & & 16.67 & \\ & & & \end{array}$


3-Pooled values Ti \& PLA

$\begin{array}{rrrcr}\text { Samples } & \text { Bone volume(mm3) } & \text { SD } & \text { Percent bone volume (\%) } & \text { SD } \\ \text { Ti } & 7.64 & 2.10 & 15.00 & 4.13 \\ \text { PLA } & 7.04 & 2.63 & 13.83 & 5.16\end{array}$




\section{Appendix VI}

\section{Results of the Histomorphometric analysis}

\section{1-Titanium mesh group (Ti)}

\begin{tabular}{|c|c|c|c|c|c|c|}
\hline Samples & $\begin{array}{l}\text { upper half } \\
\text { calcified } \\
\text { surface area } \\
\text { (nm2) }\end{array}$ & $\begin{array}{c}\text { Upper half bone } \\
\%\end{array}$ & $\begin{array}{l}\text { Lower half } \\
\text { calcified } \\
\text { surface area } \\
(\text { mm2) }\end{array}$ & $\begin{array}{l}\text { Lower half } \\
\text { bone } \%\end{array}$ & $\begin{array}{l}\text { Total calcitied } \\
\text { tissue area } \\
\text { (mm2) }\end{array}$ & $\begin{array}{c}\text { Total bone } \\
\%\end{array}$ \\
\hline CB 63025 & 0.87 & 6.60 & 1.74 & 13.17 & 2.62 & 19.77 \\
\hline CB 63027 & 0.07 & 0.54 & 0.82 & 6.20 & 0.89 & 6.74 \\
\hline$C B \quad 63028$ & 0.69 & 5.24 & 1.30 & 9.84 & 2.00 & 15.08 \\
\hline CB 63040 & 0.00 & 0.03 & 0.77 & 5.84 & 0.78 & 5.87 \\
\hline CB 63057 & 1.77 & 13.38 & 1.56 & 11.80 & 3.33 & 25.18 \\
\hline CB 63058 & 1.17 & 8.84 & 1.04 & 7.85 & 2.21 & 16.70 \\
\hline $\begin{array}{l}\text { Ti body } \\
\text { (CB) }\end{array}$ & 0.76 & 5.77 & 1.21 & 9.12 & 1.97 & 14.89 \\
\hline CR 63025 & 1.75 & 13.25 & 1.43 & 10.80 & 3.18 & 24.05 \\
\hline CR 63027 & & & & & & \\
\hline CR63028 & 0.30 & 2.29 & 3.07 & 23.17 & 3.37 & 25.46 \\
\hline CR 63040 & 0.91 & 6.88 & 1.70 & 12.87 & 2.61 & 19.75 \\
\hline CR 63057 & & & & & & \\
\hline CR 63058 & 2.76 & 20.86 & 0.79 & 5.96 & 3.55 & 26.82 \\
\hline $\begin{array}{l}\text { Ti ramus } \\
\text { (CR) }\end{array}$ & 1.43 & 10.82 & 1.75 & 13.20 & 3.18 & 24.02 \\
\hline
\end{tabular}




\section{2-Biodegradable mesh group (PLA)}

$\begin{array}{ccccccc}\text { Samples } & \begin{array}{c}\text { upper half } \\ \text { calcified } \\ \text { surface area } \\ \text { (mm2) }\end{array} & \begin{array}{c}\text { Upper } \\ \text { half bone } \\ \%\end{array} & \begin{array}{c}\text { Lower half } \\ \text { calcified } \\ \text { surface area } \\ \text { (mm2) }\end{array} & \begin{array}{c}\text { Lower half } \\ \text { bone\% }\end{array} & \begin{array}{c}\text { Total } \\ \text { calcified } \\ \text { tissue area } \\ \text { (mm2) }\end{array} & \begin{array}{c}\text { Total hone } \\ \%\end{array} \\ \text { TB 63038 } & 0.65 & 4.92 & 0.87 & 6.57 & 1.52 & 11.49 \\ \text { TB 63042 } & 0.94 & 7.10 & 1.96 & 14.78 & 2.90 & 21.88 \\ \text { TB 63043 } & 0.22 & 1.66 & 1.16 & 8.80 & 1.38 & 10.46 \\ \text { TB 63044 } & 0.28 & 2.12 & 1.68 & 12.69 & 1.96 & 14.81 \\ \text { TB 63046 } & 0.99 & 7.48 & 0.69 & 5.21 & 1.68 & 12.69 \\ \text { TB 63047 } & 0.76 & 5.77 & 1.49 & 11.29 & 2.26 & 17.06 \\ & & & & & & \\ \text { PLA body (TB) } & 0.64 & 4.84 & 1.31 & 9.89 & 1.95 & 14.73 \\ & & & & & & \\ \text { TR 63038 } & 0.35 & 2.68 & 1.33 & 10.04 & 1.68 & 12.71 \\ \text { TR_63042 } & 1.23 & 9.27 & 1.91 & 14.46 & 3.14 & 23.73 \\ \text { TR 36043 } & 0.51 & 3.87 & 0.85 & 6.46 & 1.37 & 10.33 \\ \text { TR 63044 } & 0.50 & 3.76 & 1.83 & 13.82 & 2.33 & 17.57 \\ \text { TR 63046 } & 0.88 & 6.68 & 3.49 & 26.34 & 4.37 & 33.02 \\ \text { TR 63047 } & 0.29 & 2.17 & 0.81 & 6.14 & 1.10 & 8.31 \\ \text { PLA ramus (TR) } & 0.63 & 4.74 & 1.70 & 12.87 & 2.33 & 17.61\end{array}$

3-Pooled value Ti \& PLA

$\begin{array}{rcccccc}\text { Samples } & \begin{array}{c}\text { upper half calcitied } \\ \text { surface area }(\mathrm{mm} 2)\end{array} & \begin{array}{c}\text { Lower half } \\ \text { calcified } \\ \text { surface area } \\ (\mathrm{mmm} 2)\end{array} & \begin{array}{c}\text { Lower half } \\ \text { bone } \%\end{array} & \begin{array}{c}\text { Total } \\ \text { calcified } \\ \text { tissue area } \\ (\mathrm{mm} 2)\end{array} & \begin{array}{c}\text { Total } \\ \text { bone } \%\end{array} \\ \mathrm{Ti} & 0.94 & 7.79 & 1.42 & 9.77 & 2.23 & 16.86 \\ \text { PLA } & 0.63 & 4.79 & 1.51 & 11.38 & 2.14 & 16.17\end{array}$




\section{REFERENCES:}

Abernathy W, McDaniel M, Edwards R, Kiely K, Frazier D. Nonmetallic fixation in elective maxillofacial surgery. AORN J. 2000 Jan; 71(1):193-8. PMID: 10686651

Albrektsson, T., et al., Osseointegrated titanium implants. Requirements for ensuring a long-lasting, direct bone anchorage in man. Acta Orthop. Scand., 1981. 52: p. 55-170.

Albrektsson, T. and C. Johansson, Osteoinduction, osteoconduction and osseointegration. Eur. Spine J., 2001. 10: p. S96-S101.

Albrektsson, T., et al., Osseointegrated oral implants. J. Periodontol., 1988. 59(5): p. 287-296.

Albrektsson, T., Repair of bone grafts. Scand. J. Plast. Reconstr. Surg., 1980. 14: p. 1-12.

Axhausen, W., The osteogenic phases of regeneration of bone: a historical and experimental study. J. Bone Joint Surg, 1956. 38: p. 593.

Alonso, N., et al., Cranial versus iliac onlay bone grafts in the facial skeleton: a macroscopic and histomorphometric study. The Journal of Craniomaxillofacial Surgery, 1995. 6(2): p. 113-118.

Buser D, Dula K, Belser U, Hirt HP, Berthold H.Localized ridge augmentation using guided bone regeneration. 1. Surgical procedure in the maxilla.Int $J$ Periodontics Restorative Dent. 1993;13(1):29-45.PMID: 8330945

Buser D, Dula K, Belser UC, Hirt HP, Berthold H.Localized ridge augmentation using guided bone regeneration. II. Surgical procedure in the mandible. Int J Periodontics Restorative Dent. 1995 Feb;15(1):10-29.PMID: 7591520 
Buser D, Dula K, Hirt HP, Schenk RK.Lateral ridge augmentation using autografts and barrier membranes: a clinical study with 40 partially edentulous patients.J Oral Maxillofac Surg. 1996 Apr;54(4):420-32; discussion 432-3.

Bartee BK.A membrane and graft technique for ridge maintenance using highdensity polytetrafluoroethylene membrane (n-PTFE) and hydroxylapatite: report of four cases. Tex Dent J. 1995 May;112(5):7, 9, 11-6. PMID: 9518814

Bartee BK, Carr JA. Evaluation of a high-density polytetrafluoroethylene (nPTFE) membrane as a barrier material to facilitate guided bone regeneration in the rat mandible. J Oral Implantol. 1995;21(2):88-95. PMID: 8699509

Bartee BK.A simplified technique for ridge preservation after tooth extraction.Dent Today. 1995 Oct;14(10):62-7. Review. No abstract available.PMID: 9540647

Bartee BK.The use of high-density polytetrafluoroethylene membrane to treat osseous defects: clinical reports.Implant Dent. 1995 Spring;4(1):21-6.PMID: 7550081

Bahr W, Stricker A, Gutwald R, Wellens E. Biodegradable osteosynthesis material for stabilization of midface fractures: experimental investigation in sheep. J Craniomaxillofac Surg 1999; 27: 51-57.

Bos RRM, Boering G, Rozema FR. Resorbable poly (L-lactide)plates and screws for the fixation of zygomatic fractures. J Oral Maxillofac Surg 45:751, 1987

Branemark, P.-I., Osseointegration and its experimental background. Journal of Prosthetic Dentistry, 1983. 50(3): p. 399-410. 
Burchardt, H., The biology of bone graft repair. Clinical Orthopaedics and Related Research, 1983. 174: p. 28-42.

Boyne, P.J., The evolution of guided tissue regeneration, alveolar bone grafting. Oral Maxillofac. Surg. Clin. North America, 2001. 13(3): p. 397.

Bouwman JPB, Tuinzig DB. Biodegradable osteosynthesis in mandibular advancement: a pilot study. Br J Oral Maxillofac Surg 1999; 37: 6-10.

Cohen SR, Holmes RE, Amis P, Fitchner H, Shusterman EM. Tacks: a new technique for craniofacial fixation. J Craniofac Surg. 2001 Nov;12(6):596-602. PMID: 11711829

Carlson ER, Marx RE. Part II. Mandibular reconstruction using cancellous cellular bone grafts.J Oral Maxillofac Surg. 1996 Jul;54(7):889-97. PMID: 8676236

Chen, N.T., et al., The roles of revascularization and resorption on endurance of craniofacial onlay bone grafts i the rabbit. Past. Reconstr. Surg., 1994. 93(4): p. 714-722.

Chacon GE, Ellis JP, Kalmar JR, McGlumphy EA Using resorbable screws for fixation of cortical onlay bone grafts: an in vivo study in rabbits. J Oral Maxillofac Surg. 2004 Nov; 62(11):1396-402

Cox T, Kohn MW, Impelluso T. Computerized analysis of resorbable polymer plates and screws for the rigid fixation of mandibular angle fractures. $\mathrm{J}$ Oral Maxillofac Surg. 2003 Apr;61(4):481-7; discussion 487-8. PMID: 12684967

Dahlin C, Linde E. Healing of bone defects by guided tissue regeneration. Plast Reconstr Surg 81:672-676, 1988 
Elhakim $M$,Autogenous onlay bone grafts to the mandible : an experimental evaluation of graft cellularity and embryonic origin McGill University. Faculty of Dentistry. Dept. of Oral and Maxillofacial Surgery. Thesis (M.Sc.). 2006

Edwards RC, Kiely KD, Eppley BL. Fixation of bimaxillary osteotomies with resorbable plates and screws: experience in 20 consecutive cases. J Oral Maxillofac Surg. 2001 Mar;59(3):271-6. PMID: 11243608

Edwards RC, Kiely KD, Eppley BL . The fate of resorbable poly - L-lactic / polyglycolic acid (LactoSorb) bone fixation devices in orthognathic surgery. $\mathrm{J}$ Oral Maxillofac Surg. 2001 Jan; 59 (1):19-25. PMID: 11152185

Edwards RC, Kiely KD, Eppley BL. Resorbable fixation techniques for genioplasty. J Oral Maxillofac Surg. 2000 Mar;58(3):269-72.

Edwards RC, Kiely KD. Resorbable fixation of Le Fort(I) osteotomies. J Craniofac Surg 1998; 9: 210-214.

Enislidis G, Pichorner S, Lambert F, Wagner A, Kainberger F, Kautzky M, Ewers R.: Fixation of zygomatic fractures with a new biodegradable copolymer osteosynthesis system: Preliminary results. Int J Oral Maxillofac Surg 27:352, 1998 PMID: 9804197

Eppley BL. Use of a resorbable fixation technique for maxillary fractures JCraniofacSurg1998Jul;9(4):317-21

Eppley BL, Sadove AM, Havlik RJ. Resorbable plate fixation in pediatric craniofacial surgery. Plast Reconstr Surg. 1997 Jul; 100(1):1-7; discussion 8-13. PMID: 9207653 
Eppley BL, Prevel CD. Non-metallic fixation in traumatic midfacial fractures. J Craniofac Surg. 1997 Mar;8(2):103- PMID: 10332276

Eppley BL, Reilly M. Degradation characteristics of PLLA-PGA bone fixation devices. J Craniofac Surg 2:116, 1997

Eppley BL, Prevel CD, Sadove AM .Resorbable bone fixation: Its potential role in craniomaxillofacial trauma. J Craniomaxillofac Trauma 2:56, 1996

Eppley B, Sadove A. A Comparison of Resorbable and Metallic Fixation in Healing of Calvarial Bone Grafts. Plast Reconstr Surg 96:316-322, 1995

Enislidis G, Pichorner S, Kainberger F. LactoSorb panel and screws for repair of large orbital floor defects. J Craniomaxillofac Surg 25:316, 1997

Fearon JA. Rigid fixation of the calvaria in craniosynostosis without using "rigid" fixation. Plast Reconstr Surg. 2003 Jan;111(1):27-38; discussion 39. PMID: 12496562

Ferretti C, Reyneke JP. Mandibular sagittal split osteotomies fixed with biodegradable or titanium screws: a prospective, comparative study of postoperative stability. Oral Surg Oral Med Oral Pathol Oral Radiol Endod. 2002 May;93(5):534-7. PMID: 1207520

Fonseca, R.J., et al., Revascularization and healing of onlay particulate autologous bone grafts in primates. J. Oral Surgery, 1980. 38: p. 572.

Gray, J.C. and M.W. Elves, Early osteogenesis in compact bone. Tiss. Int., 1979. 29: p. 225-229. 
Gray, J.C., M. Phil, and M.W. Elves, Donor cell's contribution to osteogenesis in experimental cancellous bone grafts. Clin. Orthop., 1982. 163: p. 261.

Hans Pistner, Dieter R. Bendex, Joachim Muhling.poly(L lactide): along term degradation study in vivo (part (III) Analytical characterization Biomaterials. $1993 ; 14(4): 291-8$

Jensen S, Aaboe M, Pinholt E, Hjørting-Hansen E, Melsen F, Ruyter E. Tissue reaction and material characteristics of four bone substitutes. The International Journal of Oral and Maxillofacial Implants, 1996; 11: 55-66

Jensen OT, Shulman LB, Block MS, Iacono VJ. Report of the sinus concensus conference of 1996. The international Journal of Oral \& Maxillofacial Implants, 1998; 13: supplement, 11-32

Lu, M. and A.B.M. Rabie, Quantitative assessment of early healing of intramembranous and endochondral autogenous bone grafts using microcomputed tomograpgy and Q-win image analyzer. Int. J. Oral Maxillofac. Surg, 2004. 33: p. 369-376.

Karring, T., Nyman, S., Gottlow, J. \& Laurell, L. Guided tissue regeneration animal and human studies. Periodontology 2000 1, 26-35.

Kostopoulos, L. \& Karring, T. Guided bone regeneration in mandibular defects in rats using a bioresorbable polymer. Clinical Oral Implant Research (1994a). 5: 66-74

Kostopoulos, L. \& Karring T. Role of periosteum in the formation of jaw bone. An experiment in the rat. Journal of Clinical Periodontology. 1995. 22: 247-254 
Kostopoulos, L., Karring, T. \& Urgauchi, R. (1994). Formation of jaw bone tuberosities by guided tissue regeneration. An experimental study in the rat. Clinical Oral Implants Research. 1994. 5: 245-253

Kellman RM, Tatum SA. Internal fixation of maxillofacial fractures: indications and current implant technologies and materials. Facial Plast Surg. 1998;14(1):3-9. PMID: 10371889

Landes CA, Kriener S .Resorbable plate osteosynthesis of sagittal split osteotomies with major bone movement. Plast Reconstr Surg. 2003 May;111(6):1828-40. PMID: 12711942

Landes CA, Kriener S, Menzer M, Kovacs AF. Resorbable plate osteosynthesis of dislocated or pathological mandibular fractures: a prospective clinical trial of two amorphous L-/DL lactide copolymer 2-mm miniplate systems. Plast Reconstr Surg. 2003 Feb;111(2):601-10. PMID: 12560681

Li. S .McCarthy S. Further investigations on the hydrolytic degradation of poly (DL-lactide), Biomaterials. 1997, Feb;20 (1):35-44

Lu, M. and A.B.M. Rabie, Quantitative assessment of early healing of intramembranous and endochondral autogenous bone grafts using microcomputed tomograpgy and Q-win image analyzer. Int. J. Oral Maxillofac. Surg, 2004. 33: p. 369-376.

McAllister BS, Haghighat K. Bone augmentation techniques. J Periodontol. 2007 Mar;78(3):377-96. Review.PMID: 17335361

Matsumoto MA, Filho HN, Padovan LE, Kawakami RY, De Assis Taveira LA. Tissue response to poly-L-lactide acid-polyglycolic acid absorbable screws in 
autogenous bone grafts: a histologic morphological analysis. Clin Oral Implants Res. 2005 Feb;16(1):112-8

Mollaoglu N, Cetiner S, Alpaslan C, Gultekin SE, Alpar R. The early tissue response to titanium and LactoSorb screws. Dent Traumatol. 2003 Jun;19(3):13944. PMID: 12752535

Marx RE, Shellenberger T, Wimsatt J, Correa P. Severely resorbed mandible: predictable reconstruction with soft tissue matrix expansion (tent pole) grafts. J Oral Maxillofac Surg. 2002 Aug;60(8):878-88; discussion 888-9. PMID: 12149731

Marx RE. Mandibular reconstruction.J Oral Maxillofac Surg. 1993 May;51(5):466-79. Review. PMID: 8478754

Meningaud JP, Poupon J, Bertrand JC, Chenevier C, Galliot-Guilley M, GuilbertF. Dynamic study about metal release from titanium miniplates in maxillofacial surgery. Int J Oral Maxillofac Surg. 2001 Jun;30(3):185-8. PMID: 11420898

Mainil-Varlet P, Rahn B, Gogolewski S. Long-term in vivo degradation and bone reaction to various polylactides.(One-year results). Biomaterials. 1997 Feb;18(3):257-66. PMID: 9031728

Magnusson I, Batich C, Collins BR. New attachment formation following controlled tissue regeneration using biodegradable membranes. J Periodont59:1-6, 1988

Moghadam H, Sándor G, Holmes H, Clokie C. Histomorphometric Evaluation of Bone Regeneration Using Allogeneic and Alloplastic Bone Substitutes. Journal of Oral and Maxillofacial Surgery. 2004; 62:202-213 
Nuutinen JP, Clerc C, Virta T, Tormala P. Effect of gamma, ethylene oxide, electron beam, and plasma sterilization on the behaviour of SR-PLLA fibres in vitro. J Biomater Sci Polym Ed. 2002;13(12):1325-36.PMID: 12555899

Ozaki, W. and S.R. Buchman, Volume maintenance of onlay bone grafts in the craniofacial skeleton: micro-architecture versus embryologic origin. Past. Reconstr. Surg., 1998. 102(2): p. 291-299

Ozaki, W., et al., A comparative analysis of the microarchitecture of cortical membranous and cortical endochondral onlay bone grafts in the craniofacial skeleton. Past. Reconstr. Surg., 1999. 104(1): p. 139-147.

Persons BL, Wong GB. Transantral endoscopic orbital floor repairusing resorbable plate. J Craniofac Surg. 2002 May;13(3):483-8; discussion 488-9. PMID: 12040223

Pensler JM. Role of resorbable plates and screws in craniofacial surgery. J CraniofacSurg.1997Mar;8(2):129-34PMID:10332281

Pineda LM, Busing M, Meinig RP, Gogolewski S. Bone regeneration with resorbable polymeric membranes. III. Effect of poly(L-lactide) membrane pore size on the bone healing process in large defects.J Biomed Mater Res. 1996 Jul;31(3):385-94. PMID: 8806065

Quereshy FA, Goldstein JA, Goldberg JS, Beg Z. The efficacy of bioresorbable fixation in the repair of mandibular fractures: an animal study.J Oral Maxillofac Surg. 2000 Nov; 58 (11):1263-9. PMID: 11078138 
Rosenthal, A.H. and S.R. Buchman, Volume maintenance of inlay bone grafts in the craniofacial skeleton. Pastic and reconstructive surgery, 2003. 112(3): p. 802811.

Rimondini L, Nicoli-Aldini N, Fini M, Guzzardella G, Tschon M, Giardino R. In vivo experimental study on bone regeneration in critical bone defects using an injectable biodegradable PLA/PGA copolymer. Oral Surg Oral Med Oral Pathol Oral Radiol Endod. 2005Feb;99(2):148-54. PMID: 15660083

Serino G, Biancu S, Iezzi G, Piattelli A., Ridge preservation following tooth extraction using a polylactide and polyglycolide sponge as space filler: a clinical and histological study in humans. Clin Oral Implants Res.2003Oct;14(5):651-8. PMID: 12969370

Stavropoulos A, Kostopoulos L, Nyengaard J R, Karring T. Deproteinized bovine bone (Bio-Oss $($ ) $)$ and bioactive glass (Biogran () ) arrest bone formation when used as an adjunct to guided tissue regeneration (GTR). An experimental study in the rat. Journal of Clinical Periodontology 2003; 30: 636-643

Stavropoulos A, Kostopoulos L, Mardas N, Nyengaard JR, Karring T. Deproteinized bovine bone used as an adjunct to guided bone augmentation (GBA) An experimental study in the rat. Clinical Implant Dentistry and Related Research, 2001a; 3: 156-165

Surpure SJ, Smith KS, Sullivan SM, Francel PC. The use of a resorbable plating system for treatment of craniosynostosis. J Oral Maxillofac Surg. 2001 Nov;59(11):1271-5; discussion 1275-6. PMID: 11688023

Stal S, Tjelmeland K, Hicks J, Bhatia N, Eppley B, Hollier L. Compartmentalized bone regeneration of cranial defects with biodegradable barriers: an animal model. J Craniofac Surg. 2001 Jan;12(1):41-7. PMID: 11314186 
Stendel R, Krischek B, Pietila TA. Biodegradable implants in neurosurgery. Acta Neurochir (Wien). 2001; 143(3):237-43. PMID: 11460911

Sumi Y, Miyaishi O, Tohnai I, Ueda M: Alveolar ridge augmentation with titanium mesh and autogenous bone. Oral Surg Oral med Oral Pathol Oral Radiol Endod 89: 268, 2000.

Shand JM, Heggie AA. Use of a resorbable fixation system in orthognathic surgery.Br J Oral Maxillofac Surg. 2000 Aug; 38(4):335-7. PMID: 10922163

Schmidt BL, Perrott DH, Mahan D, et al. The removal of plates and screws after LeFort I osteotomy. J Oral Maxillofac Surg 56:184, 1998

Suuronen R. Biodegradable fracture-fixation devices in maxillofacial surgery. I J Oral Maxillofac Surg 1993; 22: 50-57.

Suuronen R, Pohjonen T, Vasenius J, Vainionpaa. Comparison of absorbable self-reinforced multilayer poly-1-lactide and metallic plates for the fixation of mandibular body osteotomies: an experimental study in sheep. J Oral Maxillofac Surg. 1992 Mar;50(3):255-62. PMID: 1542067

Slotte C, Lundgren D, Burgos PM. Placement of autogenic bone chips or bovine bone mineral in guided bone augmentation: A rabbit skull study. The International Journal of Oral \& Maxillofacial implants, 2003; 18: 795-806

Slotte C, Lundgren D. Augmentation of calvarial tissue using non-permeable silicone domes and bovine bone mineral. An experimental study in the rat. Clinical Oral Implant Research 1999: 10: 468-476 
Schenk R. Bone regeneration: Biological basis. In: Buser D, Dahlin C, Schenk RK (eds). Guided Bone Generation in Implant Dentistry. Chicago: Quintessence, 1994:49-100.

Schmid J, Hammerle CHF, Fluckiger L, Winkler JR, Olah AJ, Gogolewski S, Lang NP. Blood-filled spaces with and without filler materials in guided bone regeneration. A comparative experimental study in the rabbit using bioresorbable membranes. Clinical Oral Implant Researcg. 1997a:8:75-81

Schmid, J. Wallkamm, B., Hammerle, C.H.F., Gogolewski, S. \& Lang, N.P. (1997b) The significance of angiogenesis in guided bone regeneration. A case report of a rabbit experiment. Clinical Oral Implants Research.8: 244-248

Turvey TA, Bell RB, Tejera TJ, Proffit WR. The use of self-reinforced biodegradable bone plates and screws in orthognathic surgery. J Oral Maxillofac Surg. 2002 Jan; 60(1):59-65. PMID: 11757010

Tharanon W, Sinn DP, Hobar PC, Sklar FH, Salomon J. Surgical outcomes using bioabsorbable plating systems in paediatric craniofacial surgery. J Craniofac Surg 1998; 9(5):441-444.

Tuominen T, Jäsmä T, Tuukkanen J, Marttinen A, Lindholm TS, Jalovaara. Bovine bone implant with bovine bone morphogenetic protein in healing a canine ulnar defect. International Orthopaedics, 2001; 25: 5-8

Von Arx T, Kurt B. Implant placement and simultaneous ridge augmentation using autogenous bone and a micro titanium mesh: a prospective clinical study with 20 implants. Clin Oral Impl Res 10(1):24-33, 1999. 
Von Arx T, Wallkamm B, Hardt N. Localized ridge augmentation using a micro titanium mesh: a report on 27 implants followed from 1 to 3 years after functional loading. Clin Oral Impl Res 9(2): 123, 1998.

Von Arx T, Hardt N, Wallkamm B. The TIME technique: A new method for localized alveolar ridge augmentation prior to placement of dental implants. Int $\mathbf{J}$ Oral Maxillofac Implants 11: 387, 1996.

Viljanen J, Kinnunen J, Bondestam S, Majola A, Rokkanen P, Tormala P. Bone changes after experimental osteotomies fixed with absorbable self-reinforced poly-L-lactide screws or metallic screws studied by plain radiographs, quantitative computed tomography and magnetic resonance imaging .Biomaterials. 1995 Nov;16(17):1353-8. PMID: 8573675

Wiltfang J, Merten HA, Becker HJ, Luhr HG. The resorbable miniplate system Lactosorb in a growing cranio-osteoplasty animal model. J CraniomaxillofacSurg.1999Aug;27(4):207-10.PMID:10626252

Wittenberg JM, Wittenberg RH, Hipp JA. Biomechanical properties of resorbable poly-L-lactide plates and screws: a comparison with traditional systems. J Oral Maxillofac Surg. 1991 May;49(5):512-6; discussion 517-8.

Zarb, G. and T. Albrektsson, Osseointegration - a requiem for the periodontal ligament? - An editorial. Int. J. Periodont. Rest. Dent., 1991. 11: p. 88-91.

Yamada, Y., K. Nanba, and K. Ito, Effects of occlusiveness of a titanium cap on bone generation beyond the skeletal envelope in the rabbit calvarium. Clin. Oral Impl. Res., 2003. 14: p. 455-463

Yildirim M, Spiekermann H, Biesterfeld S, Edelhoff D. Maxillary sinus augmentation using xenogenic bone substitute material Bio-Oss ${ }^{\circledR}$ in combination 
with venous blood. A histologic and histomorphometric study in humans. Clinical Oral Implant Research 2000: 11:217-229 